\title{
Unemployment dynamics and the cost of business cycles
}

\author{
JeAn-Olivier Hairault * \\ Paris School of Economics (PSE) \& Paris 1 University \& IZA \\ joh@univ-paris1.fr
}

FRANÇOIS LANGOT

GAINS-TEPP (Le Mans University) \& ERMES (Paris 2 University) \& IZA

flangot@univ-lemans.fr

Sophie Osotimehin ${ }^{\dagger}$

CREST-INSEE \& Paris School of Economics (PSE) \& Paris 1 University

sophie.osotimehin@ensae.fr

February 5, 2009

\begin{abstract}
In this paper, we investigate whether business cycles can imply sizable effects on average unemployment. First, using the reduced-form of the matching model, we show that job finding rate fluctuations generate intrinsically a non-linear effect on unemployment: positive shocks reduce unemployment less than negative shocks increase it. For the observed process of the job finding rate in the US economy, this intrinsic asymmetry is sufficient to generate substantial business cycle costs. This result also holds when we allow the job finding rate to be endogenous, provided the structural model is able to reproduce its volatility. Moreover, the matching model embeds other non-linearities, which alter the average job finding rate and consequently the business cycle cost.
\end{abstract}

Keywords: Business cycle costs, unemployment dynamics, matching

JEL Codes: E32, J64

*Address: MSE, 106 Boulevard de l'Hopital, 75013 Paris, France.

${ }^{\dagger}$ We thank Guy Laroque, Etienne Lehmann, Franck Portier and Christian Zimmermann and all participants at Crest seminar (2008), Gains seminar (2008) and PSE macro seminar (2009) for helpful comments. Any errors and omissions are ours. 


\section{Introduction}

In a very famous and controversial article, Lucas (1987) argues that the costs of business cycles are negligible: using empirically plausible values for risk aversion, he shows that individuals would only sacrifice a mere $0.008 \%$ of their consumption to get rid of all aggregate variability in consumption. This leads him to argue that further improvements in stabilization policies are not the priority. This claim is completely at odds with the neoclassical synthesis and the Keynesian legacies, but also with conventional wisdom. In subjective data studies, aggregate unemployment volatility undermines the household's perceived well-being (Wolfers (2003)). Survey data also suggest substantial benefits from improved stabilization policies (Shiller (1997)).

Our objective in this paper is to show that the matching unemployment theory leads to sizable welfare costs. Due to strong non-linearities, average employment is lowered by the mere process of alternate expansions and contractions: the losses during recessions outweigh the gains during economic booms. First, the volatility of the job finding rate may affect average unemployment as the unemployment dynamics depend non-linearly on the job finding rate. Secondly, the canonical matching approach also predicts that the job finding rate depends itself in a non-linear way on the shocks hitting the fundamentals of the economic structure like productivity shocks. The cost of unemployment fluctuations has been surprisingly ignored in the matching literature despite the high interest for the cyclical volatility of unemployment following the seminal works of Andolfatto (1996) and Merz (1995), and more recently of Shimer (2005) and Hall (2005).

Following Cole and Rogerson (1999), our analysis is firstly based on the reduced form of the matching model where the job finding and separation rates are considered as exogenous stochastic processes. The use of a reduced form model has the advantage of making our results robust to several changes to the standard matching model and of easily unveiling the asymmetric impact of job finding and separation rate fluctuations on unemployment. During booms, the increase in the job finding rate is partly offset by the decrease in unemployment. In recessions, the decrease in the job finding rate is amplified by the increase in unemployment. Because of this asymmetry, average unemployment is increased by fluctuations in the job finding rate. Conversely, fluctuations in the job separation rate lower the average unemployment rate ${ }^{1}$. We show that these asymmetries explain why the volatility and the persistence of the job finding and separation rate processes are potentially key variables in the analysis of business cycle costs. More surprisingly, we find that the costs of fluctuations also depend on the structural level of unemployment. Economies in which the steady state unemployment rate is high are economies also suffering from high costs of fluctuations. For the observed process of the job finding rate in the US economy, we show that the asymmetry quantitatively matters and generates sizable business cycle costs. Conversely, the observed volatility of the separation rate is too small for

\footnotetext{
${ }^{1}$ During booms, the decrease in the job separation rate is amplified by the increase in employment. In recessions, the increase in the job separation rate is compensated by the decrease in employment.
} 
this non linearity to manifest: the volatility of the job separation rate has virtually no impact on average unemployment.

However, this reduced form approach suffers from several shortcomings. First, beyond the employment loss, one needs a better founded criterion in order to evaluate the business cycle cost. Only a structural matching model can provide a well-defined welfare cost of business cycles. Second, the reduced form analysis supposes that business cycles do not have any effect on the average job finding rate: the counterfactual stabilized job finding rate is assumed to be equal to the average job finding rate. But what if fluctuations also modify the average job finding rate? A structural matching model is then necessary to take into account how the shocks hitting the fundamentals of the economy affect the job finding rate. However, since Shimer (2005), it is well known that the standard matching model fails to generate realistic fluctuations in the job finding rate. Productivity shocks cause strong movements in wages that offset the firm's incentive to change hirings, thus dampening the variations in the job finding rate.

A matching model with rigid wages in the lines of Hall (2005) allows us to address these issues altogether. It generates enough job finding rate volatility ${ }^{2}$. Moreover, it enables us to focus on the basic mechanisms embedded in the matching function which cause the business cycles to influence the average job finding rate. The matching model naturally predicts that the job finding rate is a concave function of the vacancy-unemployment ratio. This could imply that fluctuations decrease the average job finding rate. But as the vacancy-unemployment ratio is a convex function of productivity, the impact of productivity fluctuations on the average job finding rate is a priori ambiguous. These non-linearities come from the decreasing marginal returns in the matching function. The matching elasticity to vacancy plays a crucial role in the size of the business cycle costs: the lower the elasticity, the lower the average job finding rate and the higher the business cycle costs. The internal mechanisms of the matching model then lead to quite strong additional business cycle costs when the vacancy elasticity of the matching function is sufficiently low. Typically, in the more realistic case where the vacancy elasticity is inferior to 0.5 , the average job finding rate in the fluctuating economy is inferior to the value which would be reached in the stabilized economy. Considering a version of the matching model with flexible wages and fixed hiring costs (Pissarides (2007)) allows us to generalize the view that business cycles are costly in a matching economy, even if the type of non-linearities is

\footnotetext{
${ }^{2}$ This hypothesis increases the sensitivity of the model to productivity shocks, but at the expense of the observed flexibility in wages (Pissarides (2007)). Other routes have been followed to elucidate the Shimer puzzle. Hagedorn and Manovskii (2008) show that a higher parametrization for the utility of being unemployed and a lower bargaining power for workers enable the standard matching model to yield realistic fluctuations in the unemployment rate. Whereas Hornstein et al. (2007) introduce investment-specific technological shocks, Kennan (2006) emphasizes the role of procyclical informational rents: the gain that firms obtain by being more informed than workers increases in booms. The inclusion of turnover costs (Pissarides (2007), Mortensen and Nagypal (2007) and Silva and Toledo (2008)) and match-specific technological change (Costain and Reiter (2008)) have also been investigated.
} 
naturally dependent on the structural model. Different approaches to solving the Shimer puzzle potentially lead to different stabilized job finding rates, and imply therefore different evaluations of the cost of business cycles.

All in all, these results challenge Lucas's controversial result on business cycle costs by exploring an original mechanism in a canonical framework. The literature following Lucas (1987) has mostly focused on the consequences of business cycles on the volatility of individual consumption. More precisely, because business cycles amplify individual income risks, they could generate higher welfare losses than Lucas's predictions when financial markets are incomplete. However, in as far as individual income fluctuations are transitory, the costs of business cycle are still low, even negligible (Krusell and Smith (1999)), mainly because consumption can be smoothed through capital accumulation. On the other hand, when individual income variations are more persistent, the cost of business cycles becomes substantial (Beaudry and Pages (1999), Krebs (2007), Storesletten et al. (2001)). In the literature, very few papers focus on the consequences of business cycles on average consumption. This idea has been sketched out by De Long and Summers (1988); they argue that rather than steadying economic activity at its average level, stabilization would prevent output from deviating from its potential level. Ramey and Ramey (1993) explore this mechanism in a model where firms have to pre-commit to a specific technology before starting production. In this context, stabilization enhances welfare by increasing the efficiency of production. Gali et al. (2007) emphasizes that fluctuations in markups potentially generate efficiency costs on average, but they fail to show that these costs are large when averaged across booms and recessions. Stabilization may also increase welfare through its effect on capital accumulation (Matheron and Maury (2000) and Epaulard and Pommeret (2003)). Barlevy (2004) shows that the business cycle costs become sizable when returns to investment are decreasing. Eliminating fluctuations reallocates investment from periods where the marginal return to investment is low to periods where this return is high, and therefore leads to a higher growth rate of consumption. Finally, a very recent paper by Jung and Kuester (2009) emphasizes the non-linear relation between unemployment and the job finding rate. They however propose a quite complex matching model with capital accumulation, liquidity constraints and human capital, which prevents them to clearly evaluate the basic non-linearities embedded in the matching approach. Moreover, all these additional features bring very small business cycle costs. This makes a clear difference with our paper: we aim at unveiling the mechanisms in the basic matching model, which lead to sizable business cycle costs, namely the stock-flow unemployment dynamics and the congestion effects due to decreasing marginal returns in the matching function.

The paper is organized as follows. In the second section, we use a reduced form of the matching model to investigate the consequences of the non-linearity in the unemployment dynamics. Given the observed processes of the job separation and finding rates, we then derive its implication for the costs of business cycles. The third section takes into account the non-linearity in the job 
finding rate dynamics embedded into the matching model. The last section concludes.

\section{Asymmetry in the unemployment dynamics: a reduced form approach}

We believe that labor market frictions naturally generate asymmetries in the unemployment dynamics. Because of these asymmetries, aggregate fluctuations may have an impact on average unemployment. We first present our theoretical framework, and then analyze the unemployment dynamics. Finally, a quantitative evaluation of the business cycle costs is proposed.

\subsection{Framework}

Following Cole and Rogerson (1999), our theoretical framework is based on the reduced form of the matching model. We consider unemployment dynamics as the result of exogenous job separation and job finding fluctuations. By shutting down any non linearities that may affect the job finding and separation rates, the reduced form model allows us to focus on the non linearity embedded in the unemployment dynamics.

Unemployment. The unemployment dynamics arise from the entries to and exits from employment. The former are determined by the job finding rate $p$, the latter by the separation rate $s$.

$$
u_{t+1}=s_{t}\left(1-u_{t}\right)+\left(1-p_{t}\right) u_{t}
$$

Shocks. The economy is hit only by aggregate shocks which generate some fluctuations in the job finding rate $p_{t}$ and in the separation rate $s_{t}$. The job finding rate and separation rate are exogenous with respect to $u$. This key assumption derives from the matching theory. The aggregate shocks affect linearly ${ }^{3}$ both the job finding rate and the separation rate which are assumed to follow an $\operatorname{AR}(1)$ process:

$$
\begin{aligned}
p_{t} & =\left(1-\rho_{p}\right) \bar{p}+\rho_{p} p_{t-1}+\varepsilon_{t}^{p} \\
s_{t} & =\left(1-\rho_{s}\right) \bar{s}+\rho_{s} s_{t-1}+\varepsilon_{t}^{s}
\end{aligned}
$$

The shocks $\varepsilon^{p}$ and $\varepsilon^{s}$ have a zero-mean and a standard deviation equal to $\sigma_{\varepsilon^{p}}$ and $\sigma_{\varepsilon^{s}}$ respectively. $\bar{p}$ and $\bar{s}$ denote the average job finding rate and the average separation rate respectively.

Business cycle cost. Aggregate shocks may cause average unemployment to differ from the level it would have reached in an economy without any shocks. Following the convention in the literature, we refer to the latter as the stabilized economy. How the stabilized economy is

\footnotetext{
${ }^{3}$ We assume symmetrical shocks in order to identify the endogenous asymmetries generated by equation (1). We show in Appendix D that our results are not sensitive to this hypothesis.
} 
reached is not explicitly presented, in particular nothing is said on the design and the efficiency of stabilization policies. It can be argued that the business cycle cost gives an upper bound of the benefits of stabilization policies.

The cost of fluctuations is the cost of being in an economy hit by aggregate shocks, rather than being in an economy without aggregate shocks. In the former economy, the job finding rate and the separation rate fluctuate around their means, whereas in the latter they are set forever at their average value $\bar{p}$ and $\bar{s}$. The stabilized unemployment (or the structural unemployment) is equal to:

$$
\bar{u}=\frac{\bar{s}}{\bar{s}+\bar{p}}
$$

The percentage of aggregate employment lost in the business cycle is then given by:

$$
\lambda_{u}=\frac{1-\bar{u}}{1-\mathbb{E}(u)}-1=\frac{\mathbb{E}(u)-\bar{u}}{1-\mathbb{E}(u)}
$$

with $\mathbb{E}(u)$ the unconditional expectation of unemployment. Traditionally, since Lucas (1987), the business cycle cost is defined as the percentage of the consumption flow that agents would accept sacrificing in order to get rid of aggregate fluctuations. To what extent employment losses are transformed into welfare costs depends on the links between employment, income and consumption. This issue requires a more structural approach and we will show in Section 3 that employment loss can be considered as a good approximation of the welfare costs in a matching economy. But it is already straightforward that the employment loss $\lambda_{u}$ is necessarily of the same order of magnitude as the welfare cost in an economy populated by risk-neutral agents without savings.

\subsection{The analysis of the non-linearities in the unemployment dynamics}

By considering equation (1), it is fairly intuitive that shocks on the job finding rate $\left(\Delta p_{t} \equiv \bar{p}-p_{t}\right)$ and on the separation rate $\left(\Delta s_{t} \equiv \bar{s}-s_{t}\right)$ have non linear effects on unemployment. Let us rewrite the unemployment dynamics in deviation to the steady state unemployment $\left(\Delta u_{t} \equiv u_{t}-\bar{u}\right)$ :

$$
\Delta u_{t+1}=\underbrace{(1-\bar{s}-\bar{p}) \Delta u_{t}}_{\text {propagation }}-\underbrace{\Delta p_{t} u_{t}}_{\text {p-impact }}+\underbrace{\Delta s_{t}\left(1-u_{t}\right)}_{\text {s-impact }}
$$

The way shocks on the job finding and separation rates are propagated is symmetric between expansions and recessions. By contrast, the impact of these shocks depends on the level of unemployment. During booms, the decline in unemployment offsets the increase in the job finding rate. As a result, fluctuations in the job finding rate tend to increase average unemployment. On the contrary, as unemployment is higher during a recession, the job finding rate shocks have a greater impact in recession; the decline in the job finding rate is magnified by the increase in unemployment. The asymmetry stems from the difference in unemployment (or equivalently 
in employment) between recessions and booms. The greater is the difference, the greater is the asymmetry. Furthermore, the longer are booms and recessions, the greater are these effect: at the extreme limit, the increase in the job finding rate would be no longer operative if the expansion made unemployment disappear. During booms, the flows out of unemployment are weaker and weaker.

Conversely, as the impact of the job separation rate shocks depends on the level of employment, the fluctuations in the separation rate lead unemployment to decrease more in booms than to increase in recession: fluctuations in the job separation rate tend to reduce average unemployment.

In this section, we assess precisely these different effects. First, as it is traditionally done in the matching approach with aggregate shocks (see for instance Hall (2005)), a steady state analysis of equation (1) is conducted and so fluctuations in the conditional steady states are considered. This analysis delivers very easily the basics of the non-linearity embedded in the unemployment fluctuations. This simple framework highlights the importance of the volatility of the job finding and separation rates for the size of business cycle costs, but also the less expected role played by the structural unemployment rate. Secondly, taking into account the inertia embedded in equation (1), we derive the full non-linear properties of the unemployment dynamics and show that the persistence of the aggregate shocks also matters.

\subsubsection{Steady state analysis}

Let us assume for now that the speed of convergence of unemployment is infinite: fluctuations cause unemployment to jump directly from one conditional steady state to another. A conditional steady state unemployment corresponds to the level $\widetilde{u}_{i}$ toward which the unemployment rate would converge if the separation and job finding rates forever keep the same value $p_{i}$ and $s_{i}$, i.e. if the economy remains in the same state $i$. Let us define $\pi_{i}$ the unconditional probability of being in state $i$. The value taken by $p$ and $s$ in each state $i$ and the probability associated $\pi_{i}$ define the Markov chains associated with $p$ and $s$, consistently with equations (2) and (3). The average job finding rate $\bar{p}$ is therefore equal to $\sum_{i} \pi_{i} p_{i}$ and the average separation rate $\bar{s}$ to $\sum_{i} \pi_{i} s_{i}$. Jointly, they determine the structural unemployment rate $\bar{u}$. On the other hand, as unemployment is assumed to jump directly from one conditional steady state to another, the average unemployment in this economy is then equal to the average of the conditional steady states:

$$
\tilde{u}=\sum_{i} \pi_{i} \widetilde{u}_{i}
$$

The non-linearity embodied in equation (1) implies that average unemployment $\tilde{u}$ has no reason to coincide with structural (stabilized) unemployment $\bar{u}$. 


\section{Job finding rate shocks}

To understand the specific role of the non linearity in job findings, let us assume first that the separation rate is constant and equal to its mean $\bar{s}$. This non-linearity implies that $\widetilde{u}_{i}$ is a convex function of the state-dependent job finding rate $p_{i}$ :

$$
\widetilde{u}_{i}=\frac{\bar{s}}{\bar{s}+p_{i}}
$$

Because unemployment is a convex function of the job finding rate, the average unemployment is higher than the structural (stabilized) unemployment $\bar{u}$, i.e. the unemployment level in the counterfactual economy where the job finding rate is forever set at its mean $\bar{p}$ :

$$
\bar{u}=\frac{\bar{s}}{\bar{s}+\bar{p}}<\widetilde{u}=\sum_{i} \pi_{i} \widetilde{u}_{i}
$$

Figure 1 illustrates this result with a simple numerical example. Let us consider that the job finding rate can take only two values $p_{L}=0.3$ or $p_{H}=0.6$. For a job destruction rate of $3.5 \%$, unemployment fluctuates between the two conditional steady states $\widetilde{u}_{L}=10.4 \%$ and $\widetilde{u}_{H}=5.5 \%$. If the two states are equiprobable, unemployment is on average $8 \%$ in this volatile economy; largely above the stabilized economy unemployment rate. If the job finding rate was steady at $\bar{p}=0.45$, unemployment would be equal to $7.2 \%$. In this stylized example, business cycles increase unemployment by 0.8 percentage point.

Figure 1: Convexity in steady state unemployment

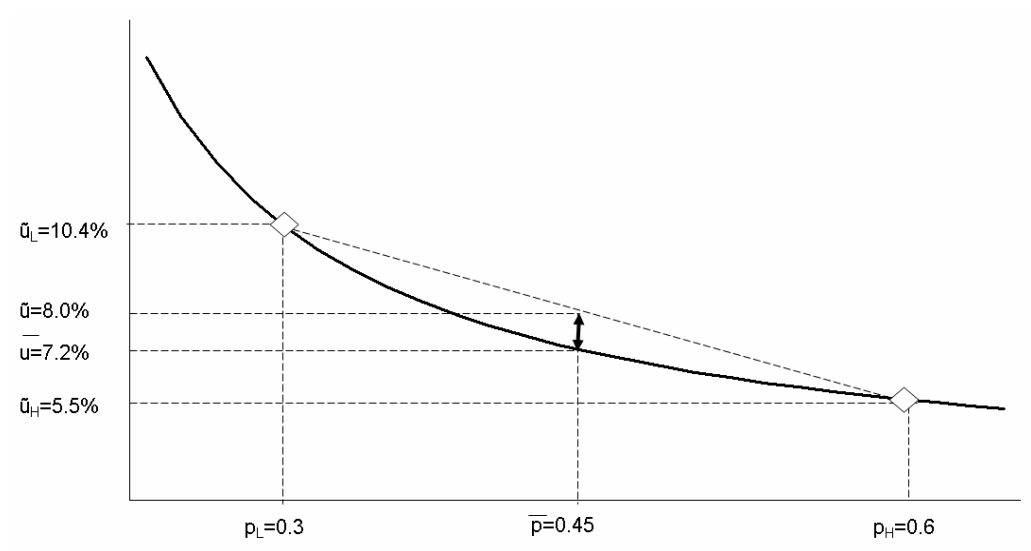

It is fairly intuitive that the gap between average unemployment $\widetilde{u}$ and stabilized unemployment $\bar{u}$ depends on the unconditional variance $\sigma_{p}^{2}$ of the job finding rate. For uniformly small deviations, using a second order Taylor expansion of equation (4), this gap can be written as ${ }^{4}$ :

$$
\tilde{u}-\bar{u} \approx \frac{\bar{s}}{(\bar{s}+\bar{p})^{3}} \sigma_{p}^{2}
$$

\footnotetext{
${ }^{4}$ See Appendix A for the derivation.
} 
A mean-preserving increase in the volatility leads to a larger difference between the stabilized and fluctuating economies. The more volatile the economy, the greater the business cycle cost.

Equation (5) indicates that the unemployment gap also depends on the mean of the job finding rate and of the separation rate. A lower value of $\bar{p}$ or a higher value of $\bar{s}$ imply a more convex economy. This result is important as it generates strong interactions between structural and cyclical unemployment. Furthermore, this suggests that labor market institutions affect the costs of fluctuations as they have an impact on the average job finding and separation rates.

\section{Job separation rate shocks}

So far, the separation rate was assumed to be constant. However, it appears clearly from equation (1) that the asymmetry in the unemployment dynamics could also come from fluctuations in the separation rate. The resulting unemployment gap would then read:

$$
\widetilde{u}-\bar{u} \approx-\frac{\bar{p}}{(\bar{s}+\bar{p})^{3}} \sigma_{s}^{2}
$$

with $\sigma_{s}^{2}$ the unconditional variance of the separation rate. Contrary to the job finding rate case, fluctuations in the separation rate tend to reduce average unemployment. Job separations decrease more in expansion than they increase in recessions. As shown by equation (6), the unemployment gap depends on the average job finding and separation rate. An increase in either of these variables weakens the impact of fluctuations on average unemployment. Further, the asymmetry embodied in equation (1) translates into average unemployment only if the separation rate is volatile enough.

Figure 2: Concavity in steady state unemployment

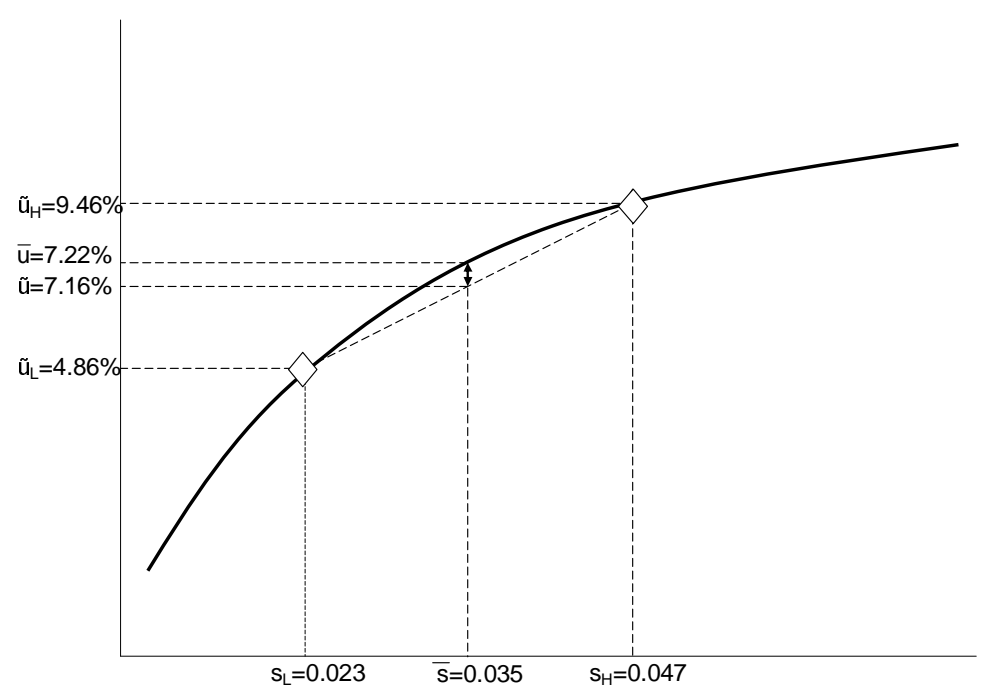

Figure 2 illustrates this result with a simple numerical example. Let us consider that the separation rate can take only two values $s_{L}=0.023$ or $s_{H}=0.046$, which correspond to a 
standard deviation of the same relative magnitude as in the job finding example. For a job finding rate of $45 \%$, unemployment fluctuates between the two conditional steady states $\widetilde{u}_{H}=9.46 \%$ and $\widetilde{u}_{L}=4.86 \%$. If the two states are equiprobable, unemployment is on average $7.16 \%$ in this volatile economy, below the stabilized economy unemployment rate. If the job separation rate was steady at $\bar{s}=0.035$, unemployment would be equal to $7.22 \%$. In this stylized example, business cycles decrease unemployment by 0.05 of a percentage point. It is remarkable ${ }^{5}$ that the same standard deviation of roughly $33 \%$ for the job finding and separation rates leads to a very different magnitude for the absolute level of the unemployment gap $\widetilde{u}-\bar{u}$.

\subsubsection{Considering unemployment inertia}

All previous calculations have been made with the assumption that unemployment jumps directly to the conditional steady states. Under this assumption, average unemployment in the business cycle economy is equal to the average of the steady states $\tilde{u}$. This equality is no longer valid once we take into account unemployment inertia. Let us explore the implications of this inertia in the case where unemployment fluctuations are caused only by job finding rate shocks ${ }^{6}$. Combining equation (1) and (4), the dynamics of unemployment can be rewritten:

$$
u_{t+1}=u_{t}+\left(\bar{s}+p_{i}\right)\left(\widetilde{u}_{i}-u_{t}\right)
$$

Contrary to the previous section, unemployment does not jump to its conditional steady states ; it converges toward the level $\widetilde{u}_{i}$ at rate $\bar{s}+p_{i}$. Because of unemployment inertia, the asymmetry embodied in the conditional steady state does not necessarily manifest in average unemployment. This asymmetry affects the average unemployment rate only if the effect of aggregate shocks is persistent enough.

An illustration. Let us illustrate this intuition by considering again the numerical example of section 2.2.1. The job finding rate can take two values $p_{L}=0.3$ or $p_{H}=0.6$. Figure 3 shows the adjustment path of unemployment from its stabilized level towards its respective conditional steady states $u_{L}=10.4 \%$ and $u_{H}=5.5 \%$. As shown in the right hand side of Figure 3 , the dynamics of unemployment are identical in the first periods following the shock. The difference between recession and expansion arises only if either lasts long enough. The additional unemployment caused by business cycles depends not only on the mean and the volatility of the aggregate shocks, but also on their persistence. We also expect some interactions between the level of asymmetry and persistence. The higher the variance of shocks, the greater the consequence of persistence ${ }^{7}$.

\footnotetext{
${ }^{5}$ We will investigate this point further in the quantitative section.

${ }^{6}$ The analysis is similar in the case where the job separation rate is fluctuating.

${ }^{7}$ Note that the asymmetry in the convergence rate amplifies the role of persistence. As pointed out by Cole and Rogerson (1999), the rate at which unemployment converges toward its conditional steady states depends on the
} 
Figure 3: The role of persistence
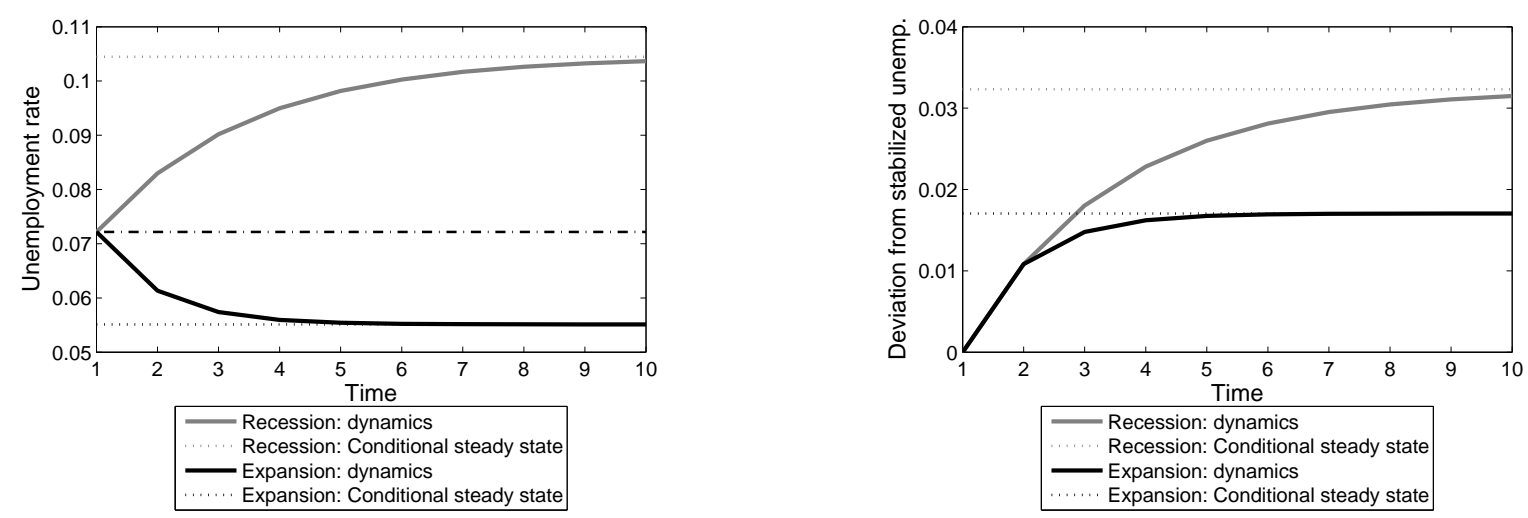

Some analytical results. To see in a synthetic formula the role of the mean, the volatility and the persistence of aggregate shocks, let us solve equation (1). We compute average unemployment in the case where only the job finding rate is fluctuating. Rewrite simply the unemployment dynamics in the following way:

$$
u_{t+1}=\bar{s}+\phi_{t} u_{t}
$$

where $\phi_{t} \equiv 1-\bar{s}-p_{t}$ and $\mathbb{E}[\phi] \equiv \bar{\phi}=1-\bar{s}-\bar{p}$. The autoregressive process defined by equation (2) implies that $\phi_{t}$ follows an autoregressive stationary process:

$$
\phi_{t}=\rho_{p} \phi_{t-1}+\left(1-\rho_{p}\right) \bar{\phi}-\varepsilon_{t}^{p}
$$

A backward substitution gives:

$$
\mathbb{E}[u]=\bar{s}\left(1+\sum_{k=0}^{+\infty} \mathbb{E}\left[\prod_{j=0}^{k} \phi_{t-j}\right]\right)
$$

As shown in Appendix B, the additional unemployment created by business cycles can then be approximated by ${ }^{8}$ :

$$
\mathbb{E}[u]-\bar{u} \approx \bar{s} \underbrace{\frac{\sigma_{\varepsilon^{p}}^{2}}{1-\rho_{p}^{2}}}_{\text {Exo. variance }} \underbrace{\sum_{k=2}^{+\infty}(1-\bar{s}-\bar{p})^{k-2} \sum_{i=0}^{k-1}(k-1-i) \rho_{p}^{i+1}}_{\text {Endogenous Propagation }}
$$

aggregate state. The rate of convergence toward its conditional steady state $\widetilde{u}_{i}$ is equal to $\bar{s}+p_{i}$. Unemployment in the volatile economy is "biased" toward favorable aggregate states as the speed of adjustment is higher in those sates.

${ }^{8}$ The approximation consists of neglecting moments of order above 2 . This is line with our approach : as we want to understand how symmetrical shocks can yield non symmetrical effects on unemployment, we disregard in particular the consequences of non-zero skewness 
The difference between average and stabilized unemployment depends on the exogenous volatility of $p$ and on the propagation of these shocks which in turn results from the exogenous persistence $\rho_{p}$ and the unemployment inertia. If $p_{t}$ and hence $\phi_{t}$ were not serially correlated $\left(\rho_{p}=0\right)$, fluctuations in the job finding rate would not affect average unemployment. Average unemployment in the business cycles and in the stabilized economy would be identical: $\mathbb{E}[u]=\bar{u}$. When aggregate shocks are persistent, average unemployment in the business cycle economy is no longer equal to stabilized unemployment. Volatility then matters: the greater the variance of job finding rate shocks, the higher the unemployment rate. In line with our intuition, equation (8) also shows some interactions between the volatility, the persistence and the mean of the job finding rate. An increase in the variance of the shocks raises average unemployment all the more so when the average job finding rate is low and the persistence of the shocks is high. The magnitude of business cycle costs will then depend on the observed characteristics of the job finding rate shocks. Business cycle costs also depend on the average separation rate : like the persistence and the mean of the job finding rate, the level of the separation rate can amplify the costs generated by job finding rate fluctuations.

Symmetrically, in the case where only the separation rate is fluctuating, the gain of fluctuations positively depends on the volatility and on the persistence of the separation rate ${ }^{9}$ :

$$
\mathbb{E}[u]-\bar{u} \approx-\frac{\sigma_{\varepsilon^{s}}^{2}}{1-\rho_{s}^{2}}\left[\sum_{k=1}^{+\infty}(1-\bar{s}-\bar{p})^{k-1} \sum_{i=0}^{k-1} \rho_{s}^{i+1}-\sum_{k=2}^{+\infty} \bar{s}(1-\bar{s}-\bar{p})^{k-2} \sum_{i=0}^{k-1}(k-1-i) \rho_{s}^{i+1}\right]
$$

Again, the average job separation and finding rates interact with the volatility and the persistence of the shocks.

\subsection{Quantifying the welfare cost of business cycles}

To investigate whether observed fluctuations in the job finding and separation rates affect average unemployment and hence the costs of business cycles, it is necessary to estimate the $\operatorname{AR}(1)$ processes ${ }^{10}$ described by equations (2) and (3). As equations (8) and (9) give only an approximation of average unemployment, we resort to simulations to obtain a more accurate estimate of the costs of business cycles. Consistently with the AR(1) estimations, we simulate job finding and separation shocks in order to obtain artificial series for the job finding and separation rates. We then use them to simulate equation (1), which allows us to compute the average unemployment rate in the business cycle economy and the business cycle costs.

\footnotetext{
${ }^{9}$ We checked numerically that the difference in the brackets is positive.

${ }^{10}$ It must be emphasized that considering a log-normal distribution for $p$ and $s$ would have led to very similar results. See Appendix D for more details.
} 


\subsubsection{Data}

The behavior of job finding and job separation rates over the business cycle is still a debated subject. It especially depends on the underlying conception of "unemployment". Contrary to Shimer (2005), Hall (2005) uses a measure of unemployment expanded to include "discouraged workers" and "marginally attached workers". Although those workers are classified as being out of the labor force, their behavior is close to that of workers classified as unemployed. Indeed, there are significant worker flows between out of the labor force and employment (Blanchard and Diamond (1990)). Cole and Rogerson (1999) argue that a model with only two labor market states (employed and unemployed) must be calibrated with care, using data including people who can be in a third labor market state (not in the labor force). Taking into account, as Hall (2005) does, the transitions between out of the labor force and employment seems to be a reasonable way of dealing with this issue. Moreover, this approach seems particularly relevant in an analysis of the business cycle costs. Although our benchmark result is based on Hall's data, we also provide the results obtained when Shimer's approach is used.

\section{The job finding rate}

The Hall (2005) and Shimer (2005) measures of the job finding rate both exhibit pro-cyclicality. The job finding rate plunges at each recession and recovers at each expansion (Figures 7 and 8, Appendix C). Both measures show a downward trend in the 1970s and in the early 1980s. As some of these movements could be due to factors unrelated to business cycles, we primarily focus hereafter on series detrended by a low frequency filter ${ }^{11}$. However, note that two elements call for not detrending the data. First, the downward trend does not necessarily result from non cyclical factors ; it could also be explained by the increase in the frequency of recessions observed during the 1970s. Secondly, as the mechanism studied in this paper relies on non linearities, the method used to isolate the cyclical component of the job finding rate could affect the cost of fluctuations. This is why non detrended (raw) data are also considered hereafter.

Table 1: Job finding rate statistics

\begin{tabular}{|c|c|c|c|c|}
\hline & \multicolumn{2}{|c|}{ Hall data } & \multicolumn{2}{|c|}{ Shimer data } \\
\hline & Raw & Detrended & Raw & Detrended \\
\hline Mean $\bar{p}$ & \multicolumn{2}{|c|}{0.285} & \multicolumn{2}{|c|}{0.450} \\
\hline Standard deviation $\sigma_{p}$ & 0.084 & 0.069 & 0.068 & 0.053 \\
\hline Autocorrelation & 0.942 & 0.913 & 0.939 & 0.915 \\
\hline
\end{tabular}

\footnotetext{
${ }^{11}$ As in Shimer (2005), we used a Hodrick-Prescott filter with smoothing parameter $10^{5}$.
} 
We then estimate the parameters characterizing the process of the job finding rate as described by equation (2). As expected, the "expanded job finding rate" has a lower mean than Shimer (2005)'s measure (Table 1). As shown in the previous section, this may exacerbate the asymmetry in the unemployment dynamics and induce larger business cycles costs. More importantly, including low intensive job seekers also implies a higher variability ${ }^{12}$. Hall (2005)'s measure should therefore lead to a higher cost of business cycles. On the other hand, these figures are quite sensitive to the use or not of the HP filter.

\section{The job separation rate}

The discrepancy between Shimer's and Hall's measures of the separation rate is also noteworthy. Hall (2005) computes a series for the overall separation rate (which includes layoffs, quits, end of short-term contracts) from gross flows on separations. By contrast, Shimer (2005) focuses only on transitions from employment to unemployment. He infers the job separation rate from short term unemployment. As for the job finding rate, Hall's measure includes worker flows between employment and not being in the labor force. Although both series capture the NBER dated recessions quite well, their trends are completely opposed (Figures 9 and 10, Appendix C). Furthermore, Hall's job separation rate is 10 times less volatile than Shimer's for a similar persistence (Table 2).

Table 2: Job separation rate statistics

\begin{tabular}{l|cc|cc}
\hline & \multicolumn{2}{|c|}{$\begin{array}{c}\text { Hall data } \\
\text { Raw }\end{array}$ Detrended } & Raw & Detrended \\
\hline \hline Mean $\bar{s}$ & \multicolumn{2}{|c|}{0.031} & \multicolumn{2}{c}{0.034} \\
Standard deviation $\sigma_{s} \times 10^{2}$ & 0.058 & 0.029 & 0.540 & 0.260 \\
Autocorrelation & 0.970 & 0.872 & 0.946 & 0.756 \\
\hline Note: Quarterly average of monthly data. Sample covers 1948q3-2004q3 for \\
Hall (2005) and 1951q1-2003q4 for Shimer (2005). Following Shimer (2005), \\
both sets of data are detrended with a HP smoothing parameter of $10^{5}$.
\end{tabular}

\subsubsection{Business cycle costs with only job finding shocks}

Figure 4 illustrates the asymmetry in the unemployment fluctuations relative to the stabilized economy for a particular simulation of equation (1) corresponding to a particular draw in the estimated process of the job finding rate. Positive shocks on the job finding rate reduce unemployment less than negative shocks increase it. Therefore average unemployment in the business cycle economy (dashed line) is above the unemployment rate in the stabilized economy (solid line).

\footnotetext{
${ }^{12}$ Table 1 shows the standard deviation of the job finding rate, and not of its innovation.
} 
Figure 4: Asymmetry in the unemployment dynamics, Hall data, detrended

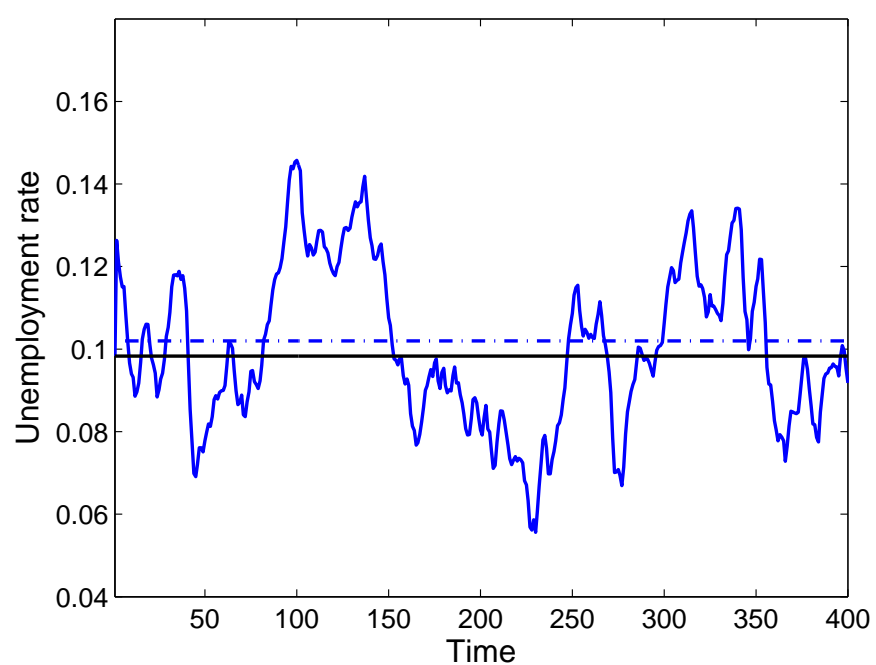

Table 3: Average unemployment and job finding rate fluctuations

\begin{tabular}{l|cc|cc}
\hline \multirow{2}{*}{} & \multicolumn{2}{|c|}{ Hall data } & \multicolumn{2}{c}{ Shimer data } \\
& Raw & Detrended & Raw & Detrended \\
\hline \hline Unemployment & $10.50 \%$ & $10.22 \%$ & $7.14 \%$ & $7.08 \%$ \\
Stabilized unemployment & $9.83 \%$ & $9.83 \%$ & $7.00 \%$ & $7.00 \%$ \\
Cost of fluctuations $\lambda_{u}$ & $0.74 \%$ & $0.44 \%$ & $0.13 \%$ & $0.08 \%$ \\
\hline
\end{tabular}

Table 3 presents the employment loss due to business cycles in the US economy for the four measures of the job finding rate. Non-linearities in the unemployment dynamics are enough to generate sizable costs of business cycles. In particular, these costs are between one and two orders of magnitude greater than the costs found by Lucas (1987). The method chosen to measure the job finding rate has strong consequences on the costs of fluctuations. When some non-employed job seekers (Hall's method) are taken into account, fluctuations in the job finding rate induce at least a $0.44 \%$ employment loss. This cost increases to $0.74 \%$ if all job finding rate fluctuations are related to business cycles factors. As expected, Shimer's measure leads to lower business cycle costs: if the job finding rate is computed using only transitions from unemployment, the cost of business cycles reduces to $0.08 \%$. Such a result was expected as Shimer's job finding rate series display both a lower volatility and a higher mean (Table 1), two characteristics that we identified as cost-reducing.

As Table 4 shows, consistently with equation (8), volatility plays a crucial role in this result. The gap between the results inferred from the Shimer and Hall data comes mainly from differences in 
Table 4: Understanding the "Hall-Shimer wedge", detrended data

\begin{tabular}{l|cc|ccccc}
\hline From Shimer data & $\bar{p}, \sigma_{p}, \bar{s}, \rho_{p}$ & & $\bar{p}, \bar{s}, \rho_{p}$ & $\sigma_{p}, \bar{s}, \rho_{p}$ & $\bar{p}, \sigma_{p}, \rho_{p}$ & \multicolumn{2}{c}{$, \sigma_{p}, \bar{s}, 0.98$} \\
From Hall data & & $\bar{p}, \sigma_{p}, \bar{s}, \rho_{p}$ & $\sigma_{p}$ & $\bar{p}$ & $\bar{s}$ & $\bar{p}, \sigma_{p}, \bar{s}, 0.98$ & \\
\hline \hline Unemployment & $7.08 \%$ & $10.22 \%$ & $7.33 \%$ & $10.71 \%$ & $6.53 \%$ & $10.33 \%$ & $7.08 \%$ \\
Stabilized unemployment & $7.00 \%$ & $9.83 \%$ & $7.00 \%$ & $10.62 \%$ & $6.46 \%$ & $9.83 \%$ & $7.00 \%$ \\
Cost of fluctuations $\lambda_{u}$ & $0.08 \%$ & $0.44 \%$ & $0.35 \%$ & $0.10 \%$ & $0.07 \%$ & $0.56 \%$ & $0.09 \%$ \\
\hline
\end{tabular}

Notes: This table shows the welfare cost of fluctuations for job finding rate processes that share characteristics from both Hall (2005) and Shimer (2005) data. For instance, column 3 presents the same average job finding and separation rates and the same autocorrelation as Shimer (2005) but the same dispersion (measured by the coefficient of variation) as Hall (2005). In column 4, we modify the variance of the shocks to ensure that the relative volatility (again measured by the coefficient of variation) of the job finding rate is held constant. Regarding the persistence experiment (columns 7 and 8 ), the variance of the shocks has been to modified to maintain the unconditional variance of the job finding rate constant.

volatility. Considering a lower average job finding rate $^{13}$ for a relatively low volatility modifies only marginally the magnitude of the business cycle costs $(0.10 \%$ versus $0.08 \%)$. The same statement can be made when a different value for $s$ is considered for a given volatility $(0.07 \%$ versus $0.08 \%$ ). On the other hand, if Shimer's job finding rate was characterized by a higher level of volatility (equal to Hall's data) ${ }^{14}$, the corresponding cost of fluctuations would amount to $0.35 \%$ which is significantly different from $0.08 \%$. However, it is also significantly different from the $0.44 \%$ cost induced from Hall's data. The remaining difference is due to the influence of the average value of the job finding rate and of the separation rate. The influence of the structural unemployment then depends on the level of the volatility: the higher the latter, the higher the influence of $\bar{p}$ and $\bar{s}$. This result reveals significant interactions between structural and cyclical unemployment ${ }^{15}$. A higher structural unemployment rate amplifies the cost of business cycles when the volatility in unemployment is high. This result suggests that business cycles could reduce average employment by more in continental European countries ${ }^{16}$ which would then suffer from both higher structural unemployment and more costly unemployment fluctuations.

When we consider an arbitrarily higher persistence ${ }^{17}$ ( $\rho$ equal to 0.98 ), the cost of business cycles is higher for both Hall's and Shimer's measure, but the increase is greater when volatility and structural unemployment are higher. An increase in the persistence of shocks reinforces the

\footnotetext{
${ }^{13} \mathrm{~A}$ lower average job finding rate implicitly increases the relative volatility of the job finding rate. To understand the specific role of the mean of the job finding rate, we ensure that its relative volatility is held constant. We modify the standard deviation of the shocks to maintain the coefficient of variation constant.

${ }^{14} \mathrm{We}$ focus here on the relative volatility of the job finding rate, measured by the coefficient of variation.

${ }^{15}$ That higher unemployment is caused by a higher separation rate or a lower job finding rate influences the cost of fluctuations only marginally.

${ }^{16}$ To the best of our knowledge, job finding rate data for European countries do not go back enough to infer their cyclical properties. Petrongolo and Pissarides (2001) have constructed series for France and Spain, but these series start respectively in 1991 and in 1987. However, all empirical evidence points to a lower average job finding rate in Europe.

${ }^{17}$ The variance of the shock has been to modified to maintain the overall variance of the job finding rate constant
} 
asymmetry in the unemployment process, especially when volatility is high.

These results bring new insights to the analysis of the costs of fluctuations. Business cycle costs mainly depend on the variability of aggregate shocks, but the three characteristics of the job finding rate process deeply interact. The marginal effect of volatility crucially depends on the mean and on the persistence of the job finding rate, but also on the value of the separation rate. Furthermore, this suggests that labor market institutions have an impact on the costs of business cycles, not only because they affect the amount of volatility faced by individuals (with unemployment benefits for example), but also because they affect structural unemployment.

\subsubsection{Business cycle costs with job separation shocks}

If shocks on the job finding rate lead to business cycle costs, those on the separation rate could imply business cycle gains. Let us simulate equation (1) with job separation shocks, first without job finding rate shocks, secondly with those shocks and taking into account the covariance between the two. We again consider both Shimer's and Hall's data. Whatever the data considered, the employment gains brought by these fluctuations are negligible. They are even nil considering Hall's data which display little volatility in the separation rate. We show in Table 5 the results relative to Shimer's data. Even in this case, the volatility is not enough to generate strong asymmetries in the unemployment dynamics: the business cycle gains are of the same magnitude as the business cycle costs shown by Lucas (1987).

Table 5: The welfare cost of fluctuations in the separation rate

\begin{tabular}{l|cc|cc}
\hline & \multicolumn{2}{|c|}{ no shock on $p$} & \multicolumn{2}{c}{ two correlated shocks } \\
& Raw & Detrended & Raw & Detrended \\
\hline \hline Unemployment & $6.99 \%$ & $7.00 \%$ & $7.16 \%$ & $7.10 \%$ \\
Stabilized unemployment & $7.00 \%$ & $7.00 \%$ & $7.00 \%$ & $7.00 \%$ \\
Cost of fluctuations $\lambda_{u}$ & $-0.009 \%$ & $0.00 \%$ & $0.18 \%$ & $0.10 \%$ \\
\hline Note: The two first columns show the welfare cost of fluctuations in the case where \\
only the separation rate fluctuates. Columns 3 and 4 give the consequences of the \\
co-variance between the job finding rate and the separation rate. These results \\
are computed using Shimer (2005)'s data for which the covariance is $-1.6 .10^{-4}$ \\
(-0.8.10-4) for raw (detrended) data.
\end{tabular}

Note that this does not necessarily imply that the volatility of the separation rate does not significantly contribute to the volatility of the unemployment rate. Considering Shimer's data, Fujita and Ramey (2008) estimate that fluctuations in the separation rate account for at least $28 \%$ of the unemployment volatility. Even if the volatility in the job separations represents a significant proportion of the unemployment fluctuations in the business cycle, it fails to decrease average unemployment significantly ${ }^{18}$.

\footnotetext{
${ }^{18}$ We indeed perform here a different exercise. In the variance decomposition, the variances are weighted
} 
However, if their specific role is limited, job separation shocks can interact with job finding ones. Taking into account its covariance with the job finding rate may enhance the consequences of job finding rate fluctuations. If the separation rate is negatively correlated to the job finding rate, movements in the separation rate cause the unemployment rate to increase further during recessions and decrease further during booms. This amplifies the asymmetry in job creation between periods of boom and recession. During booms, the increase in the job finding rate is all the more offset as the separation rate amplifies the decline in unemployment. During recessions, the increase in the separation rate enhances the magnifying effect of the rise in unemployment. A negative correlation between the job finding rate and the job separation rate in the cycle could lead to exacerbate the costs induced by the job finding volatility.

We then simulate equation (1) taking into account both shocks and the observed negative correlation (equal to -0.48 and -0.59 in the raw and detrended cases respectively) between them (only for Shimer (2005)'s data). The last two columns of Table 5, compared to those of Table 3 , show how this negative correlation amplifies the welfare consequences of the job finding rate volatility. The welfare cost of fluctuations increases from $0.08 \%$ to $0.10 \%$ when considering HP filtered data, and from $0.13 \%$ to $0.18 \%$ when the data are not filtered. However, as this effect modifies only marginally the costs induced directly by the volatility in the job finding rate, we choose to disregard the fluctuations in the separation rate in the rest of the paper.

\section{Endogenizing the job finding rate: a structural approach}

The previous section showed that the observed volatility and persistence in the job finding rate lead to sizable costs of business cycles. The structural matching model is a candidate for generating such costs. However, Shimer (2005) shows that the canonical matching model fails to generate realistic fluctuations in the job finding rate. The standard deviation of the job finding rate is much greater in the data than in the model (Shimer (2005)). An increase in labor productivity increases the expected profit from a filled job, and thus firms tend to open more vacancies. But there are internal forces in this framework which partially offset the initial increase in expected profits and then dampen the incentives for vacancy creations.

There already exist in the literature different approaches which solve the Shimer puzzle ${ }^{19}$. Do

by parameters which compensate for the difference in level between $s$ and $p$. In our investigation of business cycle costs, the levels matter. Let us consider equations (5) and (6) as these simplified expressions are a good approximation of the business cycle costs when the processes of $p$ and of $s$ are highly serially correlated as in data. They show that the difference in the order of magnitude of the volatility of $p$ and $s$ is not compensated for by the coefficients which pre-multiply the variance in each equation. This is an intrinsic limitation to the impact of separation shocks on business cycle costs. It explains why the observed volatility of the separation rate is too small for this non linearity to manifest: the volatility of the job separation rate has no real impact on average unemployment.

${ }^{19}$ See for instance Hall (2005), Hall and Milgrom (2008), Pissarides (2007), Hagedorn and Manovskii (2008), 
we care about identifying the mechanism at the origin of the high fluctuations in the job finding rate? From the analysis conducted in the first part, it could be tempting to say that it is enough to know that at least one theory is able to replicate the job finding rate dynamics. Actually, we do care. Indeed, the results obtained in the first part are derived from a model in which the job finding rate is exogenous, and in which fluctuations are neutral regarding the average job finding rate. To assess the costs of fluctuations, one must take into account the consequences of stabilization on the average job finding rate. If productivity shocks and the job finding rate are linearly related, the results found in the previous section should a priori be close to the endogenous job finding rate case. But if not, the average job finding rate can then be affected by business cycles. Why do we suspect the presence of a non-linear effect of business cycles on the job finding rate? The job finding rate is a non-linear function of the labor market tightness which also depends non-linearly on productivity changes. To show and quantify these different effects, a structural model is then required and the costs of business cycles could differ according to the model specification. This last statement is all the more true as the cost of business cycles will rely on a welfare criterion consistent with the structural model. In particular, more attention must be paid to the cyclical behavior of vacancies.

The choice of the theoretical model is then crucial. The studies aiming at elucidating the Shimer puzzle emphasize different mechanisms and none seems to close the debate. We choose to study the business cycle cost implied by the wage rigidity approach as suggested initially by Hall in a first response to the puzzle. This framework fits perfectly well with our objectives: it allows us to replicate all the volatility in the job finding $\operatorname{rate}^{20}$, but also to reveal, in a very transparent way, the basic non-linearity embodied in the matching model. As the wage retroaction is neutralized in the job creation condition, it allows us to focus only on the implications of the basic non-linearity introduced by the matching function, independently of other assumptions (hiring and/or separation costs, insider/outsider wages). We then present different calibrations of the matching function elasticity in order to unveil these implications. Each replicates the job finding rate process (standard deviation and mean) ${ }^{21}$. The implied business cycle costs are not necessarily identical and equal to that obtained in the reduced-form part.

\subsection{A canonical matching model}

The model considered hereafter is a version of the matching model $\grave{a}$ la Pissarides with aggregate uncertainty and exogenous separation.

Hornstein et al. (2007), Kennan (2006), Mortensen and Nagypal (2007), Silva and Toledo (2008) and Costain and Reiter (2008)

${ }^{20}$ Note that we choose to replicate all the volatility in the job finding rate with only productivity shocks, even if it is now well-established that the volatility generated by these shocks only is lower (Pissarides (2007) and Mortensen and Nagypal (2007)).

${ }^{21}$ The persistence would be naturally matched by that of productivity shocks. 


\subsubsection{Matching technology}

Output per unit of labor is denoted by $y_{t}$ and is assumed to follow a first-order Markov process according to some distribution $G\left(y, y^{\prime}\right)=\operatorname{Pr}\left(y_{t+1} \leq y^{\prime} \mid y_{t}=y\right)$. To hire workers, firms must open vacancies at unit cost $\kappa$. Jobs and workers meet pairwise at a Poisson rate $M(u, v)$, where $M(u, v)$ stands for the flows of matches and $v$ the number of vacancies. This function is assumed to be strictly increasing and concave, exhibiting constant returns to scale, and satisfying $M(0, v)=M(u, 0)=0$. Under these assumptions, unemployed workers find a job with a probability $p(\theta)=M(u, v) / u$ that depends on the ratio of vacancies to unemployment $(\theta=v / u)$. The probability of filling a vacancy is given by $q(\theta)=M(u, v) / v$. Hereafter, we impose that the matching function is Cobb-Douglas: $M(u, v)=\varphi u^{1-\alpha} v^{\alpha}$ with $0<\alpha<1$.

The unemployment dynamics in the economy (equation (10)) are similar to equation (1), except that the job finding rate is now endogenous. Equations (11) and (12) define the job finding rate and the job filling rate respectively which depends ${ }^{22}$ on the current productivity state $y$ :

$$
\begin{aligned}
u^{\prime} & =s(1-u)+\left(1-p\left(\theta_{y}\right)\right) u \\
p\left(\theta_{y}\right) & =\varphi \theta_{y}^{\alpha} \\
q\left(\theta_{y}\right) & =\varphi \theta_{y}^{\alpha-1}
\end{aligned}
$$

\subsubsection{Workers}

Workers are risk neutral. They have no access to financial markets. This simplifying assumption is not restrictive as our results do not rely on the impossibility of individuals to smooth their income. As agents are risk-neutral, the excessive volatility of consumption implied by this assumption is not captured in the welfare calculations. The focus is here on the impact of business cycles on average consumption, which is not affected by smoothing behaviors.

Workers can either be employed or unemployed. An unemployed worker gets an unemployment benefit $z$. Employed workers receive wage $w$ until their job is destroyed (at rate $s$ ); we do not take into account on-the-job search and voluntary quits. We choose to consider that the disutilities of working and of not working are both equal ${ }^{23}$ to the same value $\chi$. It is then

\footnotetext{
${ }^{22}$ Throughout the paper the notation $x_{y}$ indicates that a variable $x$ is a function of the aggregate productivity level $y$ and $E_{y}$ is the expected value conditional on the current state $y$.

${ }^{23}$ The existence of a significant gap is quite controversial. There are not only job search costs in the disutility of not working, but also indirect costs such as psychological damage and skill obsolescence. Does it compensate for home production and the disutility of working? There are no clear empirical answers. Our choice is consistent with the fact that non employed people are supposed to search and are not specialized in home production as non participating individuals are.
} 
straightforward to derive the representative agent intertemporal preferences:

$$
\mathbb{E}_{0} \sum_{t=0}^{\infty} \beta^{t}\left(c_{t}-\chi\right)
$$

where $\mathbb{E}_{0}$ denotes the expectation operator conditional on information at time 0 and $\beta$ the discount factor.

\subsubsection{Aggregate consumption and the welfare cost of business cycles}

In our economy, aggregate consumption is equal to the aggregate production net of the vacancy costs.

$$
c=y(1-u)-\kappa v
$$

In this economy, the only source of fluctuations is the labor productivity shocks. The welfare cost of fluctuations is therefore defined relatively to a counterfactual economy, in which labor productivity remains at its average value. The welfare cost of business cycles $\lambda$ is defined as the percentage of the consumption flow that the agent would accept sacrificing in order to get rid of aggregate fluctuations:

$$
\mathbb{E}_{0} \sum_{t=0}^{\infty} \beta^{t}\left[(1+\lambda) c_{t}\right]=\mathbb{E}_{0} \sum_{t=0}^{\infty} \beta^{t} \bar{c}_{t}
$$

where $\bar{c}_{t}$ is the level of consumption in the economy without aggregate shocks. It needs to be derived from a counterfactual experiment based on an artificial economy without any shocks. The computation of welfare costs takes explicit account of the transition path to the stabilized economy. However, in order to highlight the welfare cost of business cycles in the matching economy, let us consider the following expression, which leaves aside the transition path ${ }^{24}$ :

$$
\lambda \approx \frac{\bar{c}-\mathbb{E}(c)}{\mathbb{E}(c)}=\frac{[(1-\bar{u}) \bar{y}-\kappa \bar{v}]-\mathbb{E}[(1-u) y-\kappa v]}{\mathbb{E}(c)}
$$

Business cycles are costly when they make the production net of the vacancy cost lower than its stabilized level. In order to make a link with the reduced form analysis, the welfare cost of business cycle can be written as follows:

$$
\lambda \approx \frac{(\mathbb{E}(u)-\bar{u})-\operatorname{cov}(y, 1-u)+\kappa(\mathbb{E}(v)-\bar{v})}{\mathbb{E}(c)}
$$

The first part of the welfare cost of business cycles is the employment loss $(E(u)-\bar{u})$ present in the reduced-form analysis. Let us emphasize that the size of the employment loss is not necessarily of the same magnitude in the structural model, as the job finding rate is now endogenous. The lower the average job finding rate, the higher the employment loss and the higher the welfare cost. The second part $\operatorname{cov}(y, 1-u)$ comes from the interaction between productivity and employment.

\footnotetext{
${ }^{24}$ The transition path does not significantly matter in our economy: it decreases only very slightly the business cycle cost.
} 
A positive covariance means that labor productivity booms are more profitable than slumps are costly as employment is higher in booms. This explains why a positive covariance leads to decrease the business cycle costs. Finally, the third part shows that more vacancies in the fluctuating economy than in the stabilized one generate higher costs.

\subsubsection{The value functions}

\section{The worker's utility}

Define $U_{y}$ and $W_{y}$ to be the state contingent present value of an unemployed worker and an employed worker ${ }^{25}$ :

$$
\begin{gathered}
U_{y}=z+\beta\left\{\left(1-p\left(\theta_{y}\right)\right) \mathbb{E}_{y}\left[U_{y^{\prime}}\right]+p\left(\theta_{y}\right) \mathbb{E}_{y}\left[W_{y^{\prime}}\right]\right\} \\
W_{y}=w_{y}+\beta\left\{(1-s) \mathbb{E}_{y}\left[W_{y^{\prime}}\right]+s \mathbb{E}_{y}\left[U_{y^{\prime}}\right]\right\}
\end{gathered}
$$

\section{The firm's surplus}

The firm's value of an unfilled vacancy $V_{y}$ is given by:

$$
V_{y}=-\kappa+\beta\left\{q\left(\theta_{y}\right) \mathbb{E}_{y}\left[J_{y^{\prime}}\right]+\left(1-q\left(\theta_{y}\right)\right) \mathbb{E}_{y}\left[V_{y^{\prime}}\right]\right\}
$$

with $J_{y}$ the state contingent present value of a filled job and $q\left(\theta_{y}\right)$ the probability of filling a vacancy conditionally on the productivity state $y$. When the job is filled, the firms operate with a constant return to scale technology with labor as only input. The firm's value of a job is given by:

$$
J_{y}=y-w_{y}+\beta\left\{(1-s) \mathbb{E}_{y}\left[J_{y^{\prime}}\right]+s \mathbb{E}_{y}\left[V_{y^{\prime}}\right]\right\}
$$

Free entry implies $V_{y}=0$ for all $y$. Therefore, the job creation condition is:

$$
\kappa=\beta q\left(\theta_{y}\right) \mathbb{E}_{y}\left[J_{y^{\prime}}\right]
$$

\subsubsection{Equilibrium}

The labor market equilibrium depends on the way the wage is determined in the economy. Though our benchmark is the rigid wage model, we first present the traditional equilibrium with a Nash-bargained flexible wage. It allows us to compare the non-linearities embedded in these two equilibria.

\section{Equilibrium with flexible wages.}

\footnotetext{
${ }^{25}$ For the sake of simplicity, we omit from these equations the disutility of working and not working, the lumpsum tax financing the unemployment benefits and the dividend paid by firms to workers, as these variables are assumed to be identical across individuals.
} 
When a worker and an employer meet, the expected surplus from trade is shared according to the Nash bargaining solution. The joint surplus $S_{y}$ is defined by $S_{y}=W_{y}+J_{y}-U_{y}$. The worker gets a fraction $\gamma$ of the surplus, with $\gamma$ her bargaining power. The equilibrium with flexible wages is defined by the job creation condition and the wage rule (equations (21) and (22)), plus equations (10) to (12):

$$
\begin{aligned}
\frac{\kappa}{q\left(\theta_{y}\right)} & =\beta \mathbb{E}_{y}\left[y^{\prime}-w\left(\theta_{y^{\prime}}\right)+(1-s) \frac{\kappa}{q\left(\theta_{y^{\prime}}\right)}\right] \\
w\left(\theta_{y}\right) & =\gamma\left(y+\kappa \theta_{y}\right)+(1-\gamma) z
\end{aligned}
$$

As Shimer (2005) points out, the adjustment of wages is responsible for the insensitivity of the labor market tightness to the productivity shocks. It also makes the interplay of the non-linearities in the model more complex relative to the rigid wage equilibrium, due to the retroaction of wages in the job creation condition (equation (21)).

\section{Equilibrium with rigid wages}

Incorporating wage rigidity in the matching model is a natural way to generate enough volatility. Moreover, this allows us to focus on the basic non-linearities introduced by the matching function which exist whatever the matching model considered.

Following Hall (2005), we consider a constant wage $w_{y}=w, \forall y$. This constant wage is an equilibrium solution if $z \leq w \leq \min \pi_{y}$, where $\pi_{y}$ denotes the annuity value of the expected profit $^{26}$. The wage is set at the Nash bargaining solution relative to the average state of productivity $\bar{y}$. This wage is an equilibrium wage provided it lies in the bargaining set defined by the participation constraints of the firms and the workers.

The rigid wage equilibrium is then defined by substituting equations (21) and (22) by equations (23) and (24), again in addition to the conditions (10) to (12):

$$
\begin{aligned}
\frac{\kappa}{q\left(\theta_{y}\right)} & =\beta \mathbb{E}_{y}\left[y^{\prime}-\bar{w}+(1-s) \frac{\kappa}{q\left(\theta_{y^{\prime}}\right)}\right] \\
\bar{w} & =\gamma\left(\bar{y}+\kappa \theta_{\bar{y}}\right)+(1-\gamma) z
\end{aligned}
$$

The non-linearity arising from the unemployment dynamics (u-convexity effect), equation (10), has been intensively investigated in the previous section. Let us concentrate here on the additional non-linearity that appears once $p$ is endogenous.

First of all, the job finding rate depends non-linearly on the labor market tightness (equation (11)): due to congestion effects, the return of an additional vacancy to the job finding rate is

\footnotetext{
${ }^{26}$ This annuity value is simply computed using the value an employer attaches to a new hired worker who never receives any wage:

$$
\widetilde{J}_{y}=y+\beta(1-s) \mathbb{E}_{y}\left[\widetilde{J}_{y^{\prime}}\right]
$$

The annuity value is then given by $\pi_{y}=[1-\beta(1-s)] \widetilde{J}_{y}$.
} 
decreasing. This implies an asymmetric adjustment in the job finding rate over the business cycle. The average job finding rate in the stabilized economy is potentially higher than in a economy with business cycles ( $p$-concavity effect). The lower is the elasticity $\alpha$ of the matching function to vacancies, the higher is the $p$-concavity effect. Let us emphasize that this effect tends unambiguously to create higher welfare costs as the job finding rate is lowered by the volatility of the labor market tightness, and not by its level ${ }^{27}$. Average unemployment increases without any gains in terms of vacancy reductions.

Secondly, equation (23), combined with the job filling rate condition (equation (12)), shows that the average labor market tightness could also be affected by productivity fluctuations. If expansions and recessions have the same marginal impact on the firm's profits, the free entry condition is satisfied for greater variations in job creation in booms than in recessions. This effect tends to increase the average job finding rate in the fluctuating economy $(\theta$-convexity effect). From equation (12), it can be seen that this convexity is amplified by a high elasticity $\alpha$ of the matching function to vacancies. Ceteris paribus, it leads to lower business cycle costs only in the case where the deterministic equilibrium level of employment is below its optimal value. This is the case in our economy, whatever the parameters we consider, as we impose relatively high unemployment benefits. ${ }^{28}$

These basic non-linearities are not specific to the rigid wage model. It is obvious that the flexible wage equilibrium shares the same fundamental non-linearities, as they stem from the intrinsic characteristics of the unemployment dynamics, of the job finding rate and of the job filling rate which are exactly the same in the two equilibria. However, in the flexible wage case, the $\theta$ convexity effect is modified by the retroaction of the wage in the job creation condition (equations (21) and (22)). Hence, the non-linearity between $y$ and $\theta_{y}$ also depends on the assumption about the wage bargaining process, and more generally on the particular assumptions considered, such as the existence or not of fixed hiring and separation $\operatorname{costs}^{29}$. In this sense, the flexible wage equilibrium introduces non-linearities which are not intrinsic to the matching process. The use of the rigid wage framework allows us to focus on the basic non-linearities which are common to a large class of matching models.

\subsubsection{Welfare cost and employment loss: the rigid wage case}

In addition to the $u$-convexity effect, the $p$-concavity and the $\theta$-convexity interplay to determine the cost of the business cycles in our rigid wage economy. Actually, when wages are rigid, only the effect of these non-linearities on the job finding rate and the unemployment rate really

\footnotetext{
${ }^{27}$ In this latter case, a lower labor market tightness could be welfare-improving, if the deterministic equilibrium level of employment was above its optimal value (too many vacancy costs)

${ }^{28}$ Note that this is a conservative choice with regard the size of the business cycle costs.

${ }^{29}$ See the last section for more details on this point.
} 
matters: the employment loss can be considered as a good approximation of the welfare cost. Indeed, as the production net of vacancy costs is approximately equal to labor earnings (for a discount factor $\beta$ sufficiently close to 1$)^{30}$, it is straightforward to show that:

$$
\lambda \approx \frac{\bar{w}(1-\bar{u})-\mathbb{E}(\bar{w}(1-u))}{\mathbb{E}(\bar{w}(1-u))}=\frac{\mathbb{E}(u)-\bar{u}}{1-\mathbb{E}(u)} \quad(\beta \rightarrow 1)
$$

Comparing with equation (15), the cost-decreasing effect of the covariance between productivity and employment and the cost-increasing effect of higher vacancies compensate each other for a discount factor $\beta$ sufficiently close to 1 . More generally, the wage rigidity in the business cycles makes the welfare cost very close to the employment loss.

The total impact of productivity fluctuations on the unemployment rate is then key to understand the business cycle costs. It is the result of the $u$-convexity as in the reduced-form section, but also of the $p$-concavity and of the $\theta$-convexity, as the average job finding rate is now affected by the productivity volatility. To make this point explicit, let us approximate the average unemployment using the comparative statics of the model without aggregate shocks ${ }^{31}$. It can be shown that:

$$
\begin{aligned}
\mathbb{E}(u)-\bar{u} & \approx \frac{s}{[s+\bar{p}]^{3}} \sigma_{p}^{2}-\frac{s}{[s+\bar{p}]^{2}}(\mathbb{E}(p)-\bar{p}) \\
& \approx \underbrace{\frac{s}{[s+\bar{p}]^{3}} \sigma_{p}^{2}}_{u \text {-convexity }}-\frac{s}{[s+\bar{p}]^{2}} \frac{1}{2}(\underbrace{p^{\prime \prime}(\bar{\theta})\left(\theta^{\prime}(\bar{y})\right)^{2}}_{p \text {-concavity }}+\underbrace{p^{\prime}(\bar{\theta}) \theta^{\prime \prime}(\bar{y})}_{\theta \text {-convexity }}) \sigma_{y}^{2}
\end{aligned}
$$

The first part of the welfare cost of business cycle captures the impact of the job finding rate volatility on average unemployment (u-convexity). The second part comes from the impact of the productivity volatility on the average job finding rate. It combines both the $p$-concavity and the $\theta$-convexity and thus depends on the elasticity $\alpha$ of the matching function to vacancies. This can be shown more formally as follows ${ }^{32}$ :

$$
p^{\prime \prime}(\theta)\left(\theta^{\prime}(y)\right)^{2}+p^{\prime}(\theta) \theta^{\prime \prime}(y)=\Gamma(\theta)(2 \alpha-1) \quad \Gamma(\theta)>0
$$

The stabilization of labor productivity either decreases or increases the average job finding rate, depending on the value of the elasticity of the matching function $\alpha$. The job finding rate is a concave (convex) function of labor productivity if $\alpha$ is below (above) $1 / 2$ and the stabilized job finding rate is then higher (lower) relatively to that of the volatile economy. In the case $\alpha=1 / 2$, the $\theta$-convexity and the $p$-concavity effects exactly compensate each other. In this case, the productivity fluctuations will lead to the same increase in average unemployment as in the reduced form analysis.

\footnotetext{
${ }^{30}$ In the general case, it is necessary to also take into account the dividends paid by the firms to the workers.

${ }^{31}$ The comparative static of the model without aggregate shocks can be used to approximate the dynamic stochastic model if the shocks are persistent enough. See Mortensen and Nagypal (2007) for more details.$$
{ }^{32} \Gamma(\theta)=\frac{\phi \alpha}{(1-\alpha)^{2}}\left(\frac{\beta}{\kappa(1-\beta(1-s))}\right)^{2} \theta^{3 \alpha-2}
$$ 


\subsection{Quantifying the business cycles costs}

We first calibrate the rigid wage economy. As equations (25) and (26) give only an approximation of the welfare cost of business cycles, we resort to simulations to obtain an accurate estimate.

\subsubsection{Calibration}

The model is calibrated to match US data. We calibrate the productivity process to match the US labor productivity standard deviation and persistence ${ }^{33}$. The monthly discount rate is set to $0.42 \%$. The job separation rate is set at Hall's estimate for the US economy, 0.031. We choose the elasticity of the matching function $\alpha$ to be 0.5, in Petrongolo and Pissarides (2001) range, in order to start with a structural model as close as possible to the reduced form analysis. Following Mortensen and Pissarides (1999), $\gamma$ is set at 0.5. The scale of the matching function $\varphi$ is chosen to pin down the US average vacancy-unemployment ratio. Unemployment benefits and vacancy costs are then calibrated to reproduce the volatility and the mean of the job finding rate over the cycle. These two targets are computed using Hall (2005)'s measure of the job finding rate (Table 1).

Table 6: Benchmark calibration of the matching model

\begin{tabular}{lcc}
\hline Parameter & Calibration & Target \\
\hline \hline Labour productivity & 1 & Normalization \\
$\quad$ Average & 0.90 & US data (1951-2003) \\
$\quad$ Persistence $\rho_{y}$ & $0.9 \%$ & US data (1951-2003) \\
$\quad$ Standard deviation $\sigma_{y}$ & 0.0042 & Corresponds to 5\% annually \\
Discount rate $r$ & 0.031 & Hall (2005) \\
Job destruction rate & 0.5 & Petrongolo-Pissarides (2001) \\
Elasticity of the matching function $\alpha$ & 0.5 & Mortensen and Pissarides (1999) \\
Workers' bargaining power $\gamma$ & 0.346 & Matches US average v-u ratio of 0.72 (Pissarides, 2007) \\
\hline Scale of the matching function $\varphi$ & 0.239 & Matches US average job finding rate of 0.285 and job \\
Cost of vacancy $\kappa$ & 0.796 & finding rate volatility of 0.068 \\
Unemployment benefits $z$ & & \\
\hline
\end{tabular}

\subsection{Simulation}

Table 7, Line 1, presents the results for the benchmark calibration of the rigid wage model. These results show that the average unemployment rate is higher in the fluctuating economy. This is also the case for the average labor market tightness, and so for the average vacancies as

\footnotetext{
${ }^{33}$ We use the same data as Shimer (2005), the real output per worker in the non farm business sector, detrended with a HP smoothing parameter of $10^{5}$.
} 
Table 7: The welfare cost of fluctuations in a matching model with rigid wages

\begin{tabular}{c|cccc|ccc|c}
\hline & \multicolumn{4}{|c|}{ Business cycles economy } & \multicolumn{3}{c|}{ Stabilized economy } & Cost of \\
\cline { 2 - 8 } & $E\left(u_{t}\right)$ & $E\left(p_{t}\right)$ & $\sigma_{p}$ & $E(\theta)$ & $\bar{u}$ & $\bar{p}$ & $\bar{\theta}$ & fluctuations \\
\hline \hline$\alpha=0.5$ & $10.2 \%$ & 0.285 & 0.069 & 0.72 & $9.82 \%$ & 0.285 & 0.681 & $0.44 \%$ \\
\hline$\alpha=0.4$ & $10.2 \%$ & 0.285 & 0.069 & 0.72 & $9.75 \%$ & 0.288 & 0.678 & $0.55 \%$ \\
$\alpha=0.6$ & $10.2 \%$ & 0.285 & 0.069 & 0.72 & $9.89 \%$ & 0.283 & 0.685 & $0.32 \%$ \\
\hline
\end{tabular}

well. As expected, there is no influence of productivity fluctuations on the average job finding rate as $\alpha=0.5$, and the welfare cost of business cycles is of the same magnitude as in the reduced form analysis ${ }^{34}$. The size of the business cycle cost is only determined by the u-convexity effect. We then simulate two other cases: $\alpha=0.4$ and $\alpha=0.6$ (last two lines of Table 7). The values of the parameters $\kappa$ and $z$ have been changed accordingly in order to still match the job finding rate characteristics ${ }^{35}$. Depending on $\alpha$, the US welfare cost of fluctuations could reach $0.55 \%$ or reduce to $0.32 \%$. Petrongolo and Pissarides (2001) estimate this elasticity to be between 0.3 and 0.5. This suggests that with $\alpha=0.5$, our benchmark calibration gives a lower bound of the welfare costs of fluctuations. In the more realistic case $(\alpha=0.4)$, the average job finding rate in the fluctuating economy is lower than the value which would be reached in the stabilized economy. The magnitude of the worsening in the business cycle costs is quite sizable, since it represents a third of the impact of the job finding rate's volatility and persistence. A lower elasticity strengthens the p-concavity effect and dampens the $\theta$-convexity effect. In this case, the internal mechanism of the matching model leads to quite high business cycle costs. Note that it occurs only when the labor market tightness $\theta$ (and so the job finding rate $p(\theta)$ ) is volatile enough to make the non-linearity operating. Replicating the volatility of both the labor market tightness and the job finding rate leads to sizable business cycle costs through different channels which are all at work in this structural model ${ }^{36}$.

\subsection{Non-linearities in a flexible wage economy: an illustration}

Not only the non-linearity of the job finding rate due to the matching function is not specific to the rigid wage economy, but the flexible wage case adds other sources of non-linearity which depend on the specification of the matching model considered. The different mechanisms at

\footnotetext{
${ }^{34}$ Note that the cost-decreasing effect of the covariance between productivity and employment, offset by the cost-increasing effect of higher vacancies, generates a small change in the business cycle costs relative to the employment loss (less than 0.06 percentage point compared to 0.44 ).

${ }^{35}$ Note that, in the $\alpha=0.4$ case, the rigid wage defined at the median productivity is no longer in the bargaining set. The wage is then fixed at its highest value ensuring that the firm's value is still positive $\left(w=\operatorname{argmin}_{y} \pi_{y}\right)$.

${ }^{36}$ Note that the higher volatility implied by the unfiltered job finding rate process would lead to an even more substantial business cycle cost in the $(\alpha=0.4)$ case.
} 
work could modify the consequences of fluctuations on the average job finding rate. It is not possible to check this assertion in all cases of the flourishing literature on the Shimer puzzle. Let us illustrate this point by considering the Pissarides (2007) approach which is very close to the canonical matching model ${ }^{37}$. It consists of introducing a fixed cost $K$ of recruiting, which modifies equation (18) as follows:

$$
V_{y}=-\kappa+\beta\left\{q\left(\theta_{y}\right) \mathbb{E}_{y}\left(J_{y^{\prime}}-K\right)+\left(1-q\left(\theta_{y}\right)\right) \mathbb{E}_{y} V_{y^{\prime}}\right\}
$$

The key point is that it makes the vacancy cost less dependent on the labor market tightness. In the traditional framework, following a positive productivity shock, tightness increases, and so it increases the vacancy cost, which puts a brake on the expansion of the job finding rate. In that case, when considering insider wage contracts, the equilibrium is defined by ${ }^{38}$ :

$$
\begin{aligned}
\frac{\kappa}{q\left(\theta_{y}\right)}+K & =\beta \mathbb{E}_{y}\left[y^{\prime}-w\left(\theta_{y^{\prime}}\right)+(1-s)\left(\frac{\kappa}{q\left(\theta_{y^{\prime}}\right)}+K\right)\right] \\
w\left(\theta_{y}\right) & =\gamma\left(y+\kappa \theta_{y}+\beta K p\left(\theta_{y}\right)\right)+(1-\gamma) z
\end{aligned}
$$

The additional non-linearity between $y$ and $\theta_{y}$, coming from the wage equation, results from the consideration of a fixed hiring cost and an insider wage contract. This clearly illustrates that additional non-linearities can be introduced in the matching model through alternative assumptions, leading to higher or lower business cycle costs.

Appendix $\mathrm{F}$ shows that the condition which ensures that the job finding rate is lowered by business cycles is less stringent in this flexible wage environment. Wage adjustments modify the response of vacancies to productivity shocks, which in turn alter the non-linearity in the job finding rate. For the same value of $\alpha$, the flexible wage framework leads to higher business cycle costs. All in all, this result gives new implications to the Shimer puzzle literature: the way this puzzle is solved matters for the magnitude of business cycles costs. The next question is then to determine the most empirically relevant model which will then deliver the "realistic" magnitude of the costs generated by unemployment fluctuations.

\section{Conclusion}

This paper brings new insights to the business cycle cost analysis. It shows that non-linearities in the unemployment dynamics caused by frictions on the labor market can generate sizable

\footnotetext{
${ }^{37}$ Even closer, Hagedorn and Manovskii (2008) have responded to the Shimer puzzle by suggesting that the problem is more in the way the model is calibrated than in the model itself. They show that the volatility of the job finding rate is high only if the non-market activity $z$ is calibrated sufficiently close to the average productivity. The key point is the size of the percentage changes of profits in response to (productivity) shocks. Note that it implies calibrating $z$ at a much higher value than a strict interpretation as an unemployment benefit would imply. This is not consistent with our assumption to not differentiate the disutility of working and of not working.

${ }^{38}$ Note that aggregate consumption (equation 13) is now: $c_{y}=y(1-u)+\kappa v-K * M(u, v)$.
} 
costs of fluctuations. Using a reduced-form model of the labor market, these costs are estimated to be almost two orders of magnitude greater than those computed by Lucas (1987). We also show in the rigid wage version $\grave{a}$ la Hall (2005) that the internal mechanisms of the matching model matter for the magnitude of business cycle costs as they impact the average job finding rate through different non-linearities. Our results emphasize that the welfare cost of fluctuations does not only depend on the variability of aggregate shocks. The persistence of these shocks, but also the level of structural unemployment have important implications. Furthermore, a high structural unemployment rate magnifies the welfare consequences of the volatility and the persistence of macroeconomic shocks. This suggests that business cycles may reduce average consumption by more in continental European countries which would then suffer from both higher structural unemployment and more costly unemployment fluctuations. Business cycle costs would not be alike across countries.

Overall, these first results question the optimism of Lucas (1987) about the weakness of business cycle costs. They are obtained in a very simple framework without taking into account the individual risks associated with aggregate unemployment, which has received more attention in the literature since the seminal work of Krusell and Smith (1999). Unemployment fluctuations could then imply welfare costs through both a decrease in aggregate consumption and an increase in individual consumption volatility. There are no reasons to think that these two dimensions are not cumulative ${ }^{39}$, leading to substantial business cycle costs.

In this paper, we neglect other dimensions strongly related to unemployment, which could have changed our quantitative measure of the business cycle costs. First, employment is not considered as providing extra welfare disutility relative to unemployment. This question is highly debated among the profession. Without any doubt, our choice increases the magnitude of business cycle costs. On the other hand, unemployment benefits do not lead to distortive taxation in our theoretical framework. Business cycles, by increasing average unemployment, could imply higher taxes, which would, in turn, weigh employment down. This could have been counted as a cost of business cycles. Another dimension which could magnify these costs is the loss of human capital generated by unemployment spells and reflected in the permanent decrease in wages observed in data. Is this compensated for by more intense human capital accumulation during expansions ${ }^{40}$ ? All these points would deserve to be addressed to obtain a more general assessment of the welfare cost of unemployment fluctuations.

In this paper, nothing is said about the design and the efficiency of stabilization policies. It can be argued that the business cycle cost gives an upper bound of the benefits of stabilization policies and we agree that the cost of fluctuations and the benefits of stabilization policies must be distinguished, even if they are closely connected. An estimation of stabilization policies

\footnotetext{
${ }^{39}$ The verification of this assertion is left to further research.

${ }^{40}$ Note that Jung and Kuester (2009) have recently shown that the existence of skill depreciation in unemployment spells amplifies the decrease in output when aggregate fluctuations increase average unemployment.
} 
presupposes a view of the type of shocks that may affect the economy, of the way they may affect it, but also of the amount of variability that stabilization policies can (or should) remove. As is standard in the matching literature, we assumed that labor productivity shocks are the only source of fluctuations. Considering other shocks could bring about different non-linearities, and induce different interactions with the job finding rate volatility. This question is left for further research.

From a methodological standpoint, this paper pleads for not linearizing models of business cycles. We show that the non-linearities embodied in the matching model lead to significant business cycle costs. One may suspect that the intensive use of log-linearization in the DSGE approach is misleading. This is the case for the labor market but it could be also the case for other markets. A reappraisal of business cycle models on this basis would be a fruitful area for research. 


\section{References}

Andolfatto, D. (1996), 'Business cycles and labor-market search', American Economic Review 86(1), 112-32.

Barlevy, G. (2004), 'The cost of business cycles under endogenous growth', American Economic Review 94(4), 964-990.

Beaudry, P and C. Pages (1999), 'The cost of business cycles and the stabilization value of unemployment insurance', European Economic Review 45(8), 1545-1572.

Blanchard, O. and P. Diamond (1990), 'The cyclical behavior of the gross flows of u.s. workers', Brookings Papers on Economic Activity 2, 85-143.

Cole, H. and R. Rogerson (1999), 'Can the mortensen-pissarides matching model match the business-cycle facts', International Economic Review 40(4), 933-1959.

Costain, J. and M. Reiter (2008), 'Business cycles, unemployment insurance, and the calibration of matching models', Journal of Economic Dynamics and Control 32, 1120-1155. forthcoming.

De Long, B. and L. Summers (1988), 'How does macroeconomic policy affect output?', Brookings Papers on Economic Activity 2, 433-480.

Epaulard, A. and A. Pommeret (2003), 'Recursive utility, growth, and cost of volatility', Review of Economic Dynamics 6(2), 672-684.

Fujita, S. and G. Ramey (2008), 'The cyclicality of separation and job finding rates', International Economic Review . forthcoming.

Gali, J., M. Gertler and D. Lopez-Salido (2007), 'Markups, gaps and the welfare cost of business fluctuations', Review of Economics and Statistics .

Hagedorn, M. and I. Manovskii (2008), 'The cyclical behaviour of equilibrium unemployment and vacancies revisited', American Economic Review 98(4), 1692-1706.

Hall, R. (2005), 'Employment fluctuations with equilibrium wage stickiness', American Economic Review 95(1), 50-65.

Hall, R. and P. Milgrom (2008), 'The limited influence of unemployment on the wage bargain', American Economic Review 98(4), 1653-1674.

Hornstein, A., P. Krusell and G Violante (2007), Modelling capital in matching models: Implications for unemployment fluctuations. mimeo,.

Jung, P. and K. Kuester (2009), The (un)importance of unemployment fluctuations for welfare. Federal Reserve Bank of Philadelphia Working Paper. 
Kennan, J. (2006), Private information, wage bargaining and employment fluctuations. NBER Working Papers.

Krebs, T. (2007), 'Job displacement risk and the cost of business cycles', American Economic Review 97(3), 664-686.

Krusell, P. and A. Smith (1999), 'On the welfare effects of eliminating business cycles', Review of Economic Dynamics 2(1), 245-272.

Lucas, Robert (1987), Models of Business Cycles, Blackwell Publishing.

Matheron, J. and T. Maury (2000), The welfare cost of fluctuations in ak growth models. mimeo, University of Paris.

Merz, M. (1995), 'Search in the labour markert and the real business cycle', Journal of Monetary Economics 36(2), 269-300.

Mortensen, D. and C. Pissarides (1999), Job reallocation, employment fluctuations and unemployment, Vol. 1, 1 edn, Elsevier, chapter 18, pp. 1171-1228.

Mortensen, D. and E. Nagypal (2007), 'More on unemployment and vacancy fluctuations', Review of Economic Dynamics 61, 397-415.

Petrongolo, B. and C. Pissarides (2001), 'Looking into the black box: a survey of the macthing function', Journal of Economic Literature 39, 716-741.

Pissarides, C. (2007), The unemployment volatility puzzle: Is wage stickiness the answer? The Walras-Bowley lecture, North American Summer Meetings of the Econometric Society, Duke University.

Ramey, G. and V. Ramey (1993), 'Technology commitment and the cost of economic fluctuations', NBER Working Paper No. W3755 pp. 433-480.

Shiller, R (1997), Why Do People Dislike Inflation? in Christina Romer and David Romer (eds.), Reducing Inflation: Motivation and Strategy, University of Chicago Press.

Shimer, R. (2005), 'The cyclical behaviour of equilibrium unemployment and vacancies', American Economic Review 95(1), 25-49.

Silva, J. and M. Toledo (2008), 'Labour turnover costs and the behavior of vacancies and unemployment', Macroeconomic Dynamics . forthcoming.

Storesletten, K., C. Telmer and A. Yaron (2001), 'The welfare cost of business cycles revisited: Finite lives and cyclical variation in idiosyncratic risk', European Economic Review .

Wolfers, J. (2003), 'Is business cycle volatility costly? evidence from surveys of subjective wellbeing', International Finance 6(1), 1-26. 


\section{A The unemployment asymmetry gap}

The conditional steady state can be written as a function of the job finding rate:

$$
\widetilde{u}_{i}=\widetilde{u}\left(p_{i}\right)
$$

Let $\nu_{i}=p_{i}-\bar{p}$, the conditional unemployment rate is therefore:

$$
\widetilde{u}_{i}=\widetilde{u}\left(\bar{p}+\nu_{i}\right)
$$

Because the unemployment rate is a convex function of the job finding rate, volatility in the job finding rate affects average unemployment. The unemployment gap $\psi_{p}$ between an economy characterized by a stable job finding rate and an economy with a volatile job finding rate can be computed as follows:

$$
\sum_{i} \pi_{i} \widetilde{u}\left(\bar{p}+\nu_{i}\right)=\bar{u}+\psi_{p}
$$

A second order approximation of the left hand side yields:

$$
\sum_{i} \pi_{i}\left[\widetilde{u}(\bar{p})+\nu_{i} \widetilde{u}^{\prime}(\bar{p})+\frac{\nu_{i}^{2}}{2} \widetilde{u}^{\prime \prime}(\bar{p})\right] \approx \bar{u}+\psi_{p}
$$

Which gives:

$$
\begin{aligned}
& \psi_{p} \approx \frac{\sigma_{p}^{2}}{2} \widetilde{u}^{\prime \prime}(\bar{p}) \\
& \psi_{p} \approx \sigma_{p}^{2} \frac{\bar{s}}{(\bar{s}+\bar{p})^{3}}
\end{aligned}
$$

A similar calculation gives for the job separation rate:

$$
\begin{aligned}
& \psi_{s} \approx \frac{\sigma_{s}^{2}}{2} \widetilde{u}^{\prime \prime}(\bar{s}) \\
& \psi_{s} \approx-\sigma_{s}^{2} \frac{\bar{p}}{(\bar{s}+\bar{p})^{3}}
\end{aligned}
$$




\section{B Average unemployment: analytical results}

The unemployment dynamics read:

$$
u_{t+1}=s+\left(1-s-p_{t}\right) u_{t}
$$

Define $\phi_{t} \equiv 1-\bar{s}-p_{t}$ and $\mathbb{E}[\phi] \equiv \bar{\phi}=1-\bar{s}-\bar{p}$.

$$
\phi_{t}=\rho \phi_{t-1}+(1-\rho) \bar{\phi}-\varepsilon_{t}^{p}
$$

Where $\varepsilon_{t}^{p}$ is the innovation of the job finding rate process. It is iid, has mean zero and variance $\sigma_{\varepsilon_{p}}^{2}$.

The unemployment dynamics can be written:

$$
u_{t+1}=\bar{s}+\phi_{t} u_{t}
$$

A backward substitution gives:

$$
\begin{aligned}
u_{t+1} & =\bar{s}+\sum_{k=0}^{+\infty} \prod_{j=0}^{k} \phi_{t-j} \bar{s} \\
\mathbb{E}\left[u_{t+1}\right] & =\bar{s}\left(1+\sum_{k=0}^{+\infty} \mathbb{E}\left[\prod_{j=0}^{k} \phi_{t-j}\right]\right)
\end{aligned}
$$

We can write $\phi$ infinite moving average representation:

$$
\phi_{t}=\bar{\phi}-\Sigma_{j=0}^{+\infty} \rho_{p}^{j} \varepsilon_{t-j}^{p}
$$

And the mean of unemployment can be written as:

$$
\mathbb{E}[u]=\bar{s}\left(1+\mathbb{E} \Sigma_{k=0}^{+\infty}\left[\left(\bar{\phi}-\Sigma_{j=0}^{+\infty} \rho_{p}^{j} \varepsilon_{t-j}^{p}\right) \ldots\left(\bar{\phi}-\Sigma_{j=0}^{+\infty} \rho_{p}^{j} \varepsilon_{t-j-k}^{p}\right)\right]\right)
$$

Which can be approximated by:

$$
\mathbb{E}[u] \approx \bar{s}\left(\frac{1}{1-\bar{\phi}}+\frac{\sigma_{\varepsilon^{p}}^{2}}{1-\rho_{p}^{2}} \sum_{k=2}^{+\infty}\left(\bar{\phi}^{k-2} \sum_{i=0}^{k-1}(k-1-i) \rho_{p}^{i+1}\right)\right)
$$

A similar calculation gives the consequences of job separation rate fluctuations on the average unemployment rate:

$$
\mathbb{E}[u]-\bar{u} \approx-\frac{\sigma_{\varepsilon^{s}}^{2}}{1-\rho_{s}^{2}}\left[\sum_{k=1}^{+\infty}(1-\bar{s}-\bar{p})^{k-1} \sum_{i=0}^{k-1} \rho_{s}^{i+1}-\sum_{k=2}^{+\infty} \bar{s}(1-\bar{s}-\bar{p})^{k-2} \sum_{i=0}^{k-1}(k-1-i) \rho_{s}^{i+1}\right]
$$




\section{Job finding rate and separation rate data}

Figure 5: Job finding rate - Shimer data

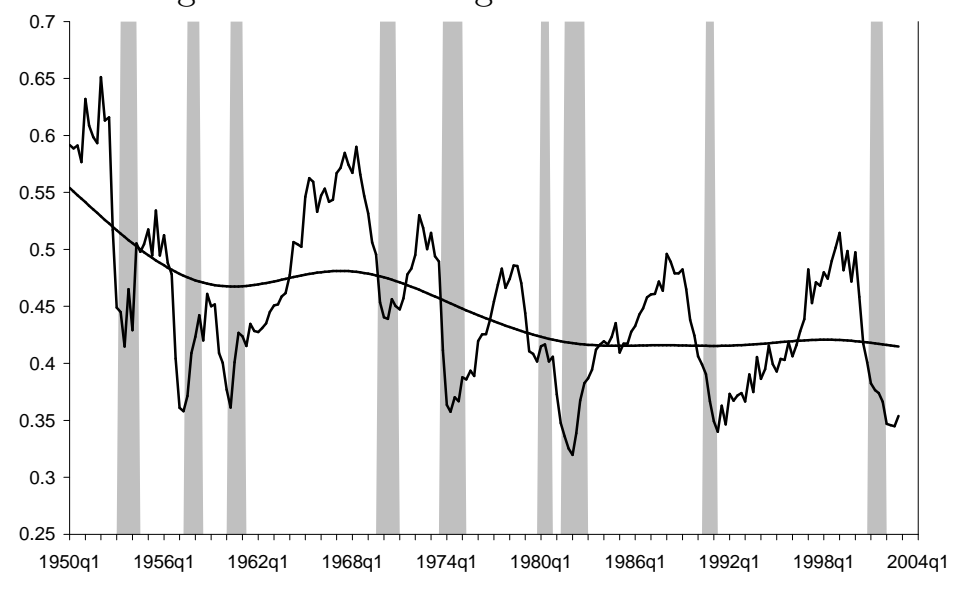

Figure 6: Job finding rate - Hall data

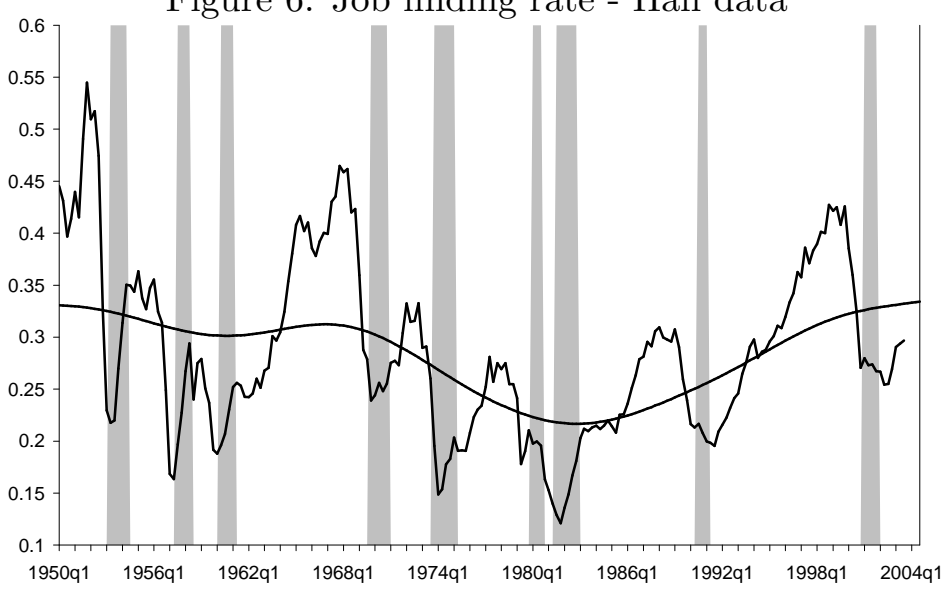


Figure 7: Separation rate - Shimer data

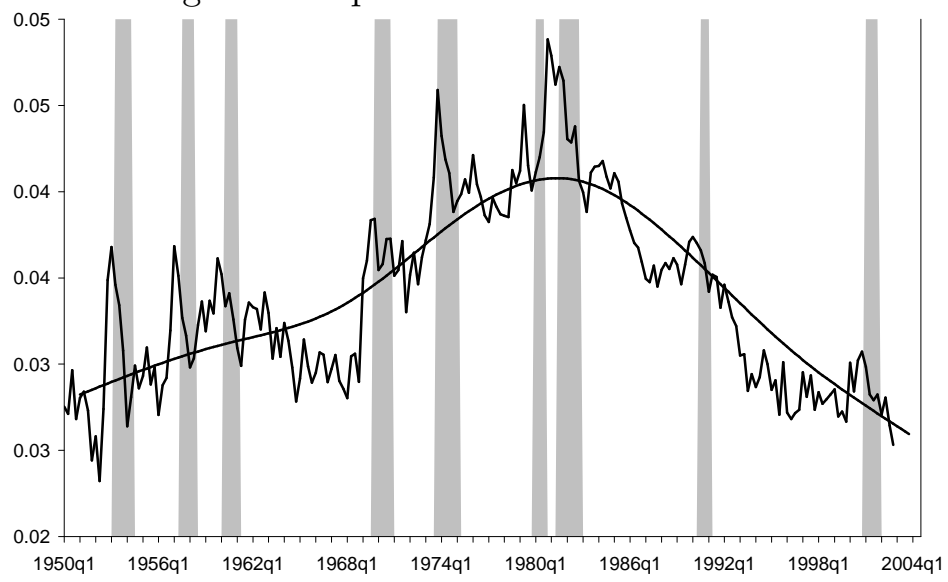

Figure 8: Separation rate - Hall data

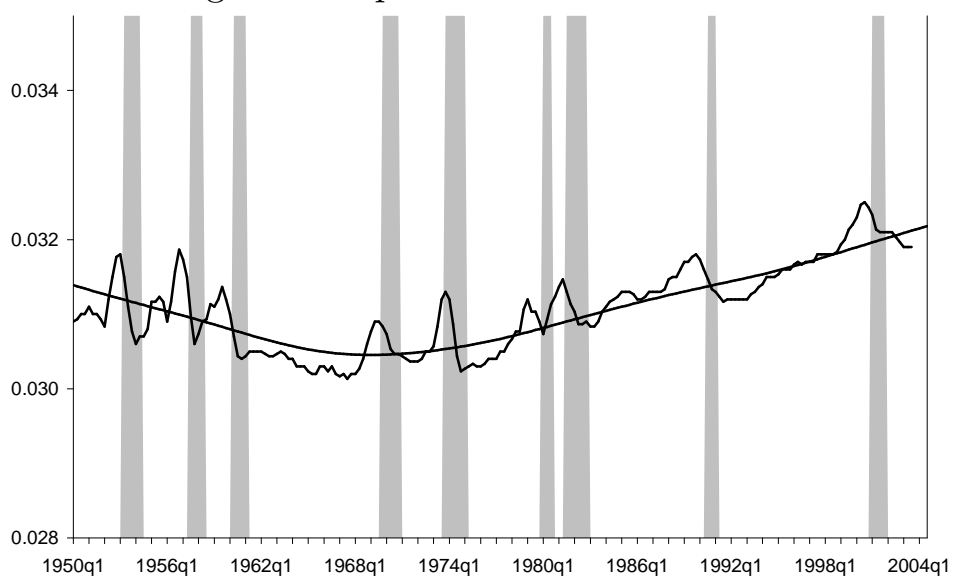

\section{Alternative specification: log-normal shocks}

We estimate the following $\mathrm{AR}(1)$ processes:

$$
\begin{aligned}
& \ln \left(p_{t}\right)=a_{l p}+\rho_{l p} \ln \left(p_{t-1}\right)+\varepsilon_{t}^{l p} \\
& \ln \left(s_{t}\right)=a_{s}+\rho_{l s} \ln \left(s_{t-1}\right)+\varepsilon_{t}^{l s}
\end{aligned}
$$

Tables 8 and 9 show that the implied characteristics for the level of $p$ and $s$ are relatively close to those displayed in Tables 1 and 2. This is particularly the case when considering H-P filtered data. Using the HP filter makes the choice of estimating in log or in level pointless. On the other hand, without filtering, it appears that the log-linearity decreases the cost of business cycles. As the distribution of $p$ is shifted to the right, the non-linear effect of the fluctuations in $p$ on $u$ is weaker: $p$ fluctuates over a less convex region (Figure 9). 
Figure 9: The implications of log-normality

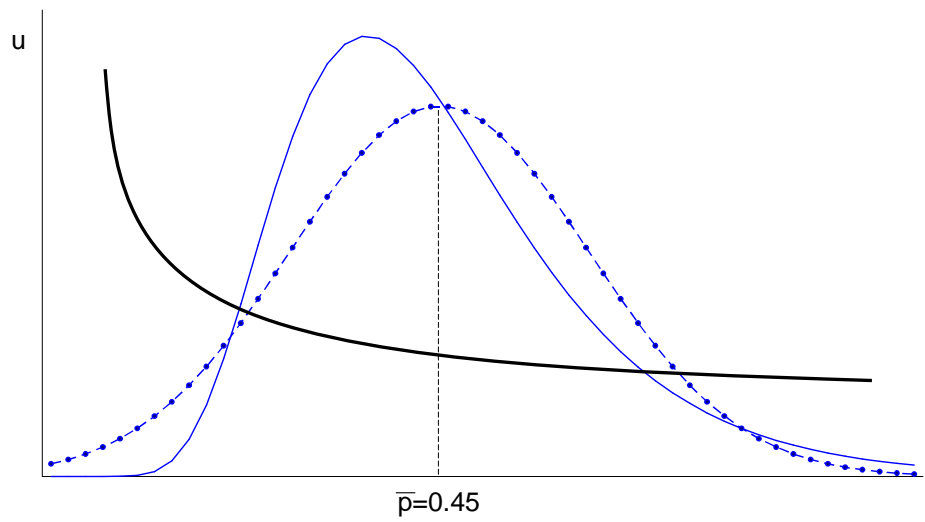

Table 8: Job finding rate fluctuations under log-normality

\begin{tabular}{|c|c|c|c|c|}
\hline & \multicolumn{2}{|c|}{ Hall data } & \multicolumn{2}{|c|}{ Shimer data } \\
\hline & Raw & Detrended & Raw & Detrended \\
\hline \multicolumn{5}{|l|}{ Estimated process of $\ln (p)$} \\
\hline Standard deviation of $\varepsilon^{l p}$ & 0.098 & 0.097 & 0.049 & 0.048 \\
\hline Autocorrelation $\rho_{l p}$ & 0.941 & 0.913 & 0.941 & 0.914 \\
\hline \multicolumn{5}{|l|}{ Implied dynamics of $p$} \\
\hline Mean $\bar{p}$ & \multicolumn{2}{|c|}{0.285} & \multicolumn{2}{|c|}{0.450} \\
\hline Standard deviation $\sigma_{p}$ & 0.084 & 0.068 & 0.068 & 0.053 \\
\hline Autocorrelation & 0.942 & 0.913 & 0.939 & 0.915 \\
\hline Business cycle cost & $0.63 \%$ & $0.43 \%$ & $0.13 \%$ & $0.08 \%$ \\
\hline
\end{tabular}

Note: Quarterly average of monthly data. Sample covers 1948q3-2004q3 for Hall (2005) and 1951q1-2003q4 for Shimer (2005). Following Shimer (2005), both sets of data are detrended with a HP smoothing parameter of $10^{5}$.

\section{E Non linearities in the endogenous job finding rate: the flexible wage case}

In this Appendix, we show that the condition ensuring the concavity of the job finding rate is less stringent when wages are flexible than when wages are rigid. We use the comparative statics of the model without aggregate shocks to approximate the response of the job finding rate.

For a level $y$ of productivity, the equilibrium vacancy-unemployment ratio $\theta$ is characterized by the following equation.

$$
H(\theta, y) \equiv \frac{\kappa}{q(\theta)}+\beta K+\frac{\gamma \beta(\kappa \theta+p(\theta) \beta K)}{1-\beta(1-s)}-\frac{\beta(1-\gamma)(y-z)}{1-\beta(1-s)}=0
$$


Table 9: Job separation rate fluctuations under log-normality

\begin{tabular}{|c|c|c|c|c|}
\hline & \multicolumn{2}{|c|}{ Hall data } & \multicolumn{2}{|c|}{ Shimer data } \\
\hline & Raw & Detrended & Raw & Detrended \\
\hline \multicolumn{5}{|l|}{ Estimated process of $\ln (s)$} \\
\hline Standard deviation of $\varepsilon^{l s}$ & 0.005 & 0.004 & 0.055 & 0.051 \\
\hline Autocorrelation $\rho_{l s}$ & 0.970 & 0.873 & 0.941 & 0.734 \\
\hline \multicolumn{5}{|l|}{ Implied dynamics of $s$} \\
\hline Mean $\bar{s}$ & \multicolumn{2}{|c|}{0.031} & \multicolumn{2}{|c|}{0.034} \\
\hline Standard deviation $\sigma_{s} \times 10^{-2}$ & 0.058 & 0.029 & 0.540 & 0.260 \\
\hline Autocorrelation & 0.970 & 0.873 & 0.946 & 0.734 \\
\hline Business cycle cost & $0 \%$ & $0 \%$ & $-0.006 \%$ & $0 \%$ \\
\hline
\end{tabular}

Let us define

$$
G(\alpha) \equiv \frac{\partial^{2} p}{\partial y^{2}}=p^{\prime \prime}(\theta)\left(\theta^{\prime}(y)\right)^{2}+p^{\prime}(\theta) \theta^{\prime \prime}(y)
$$

Using the function $H(\theta, y)$, we then obtain:

$$
G(\alpha)=\alpha(1-\alpha) \frac{[\bar{\Psi}(1-\gamma)]^{2}}{\left(\Gamma(\theta)+\gamma \bar{\Psi} \beta K p^{\prime}(\theta)\right)^{2}}\left[-\theta^{\alpha-2}+\frac{\alpha \theta^{-2}}{\Gamma(\theta)+\gamma \bar{\Psi} \beta K p^{\prime}(\theta)}\left[\kappa+\gamma \bar{\Psi} \beta K \theta^{2 \alpha-1}\right]\right]
$$

where $\bar{\Psi}=\frac{\beta}{1-\beta(1-s)}$ and $\Gamma(\theta)=-\kappa \frac{q^{\prime}(\theta)}{q(\theta)^{2}}+\frac{\gamma \beta \kappa}{1-\beta(1-s)}$

We deduce that the job finding rate is a concave function of productivity if:

$$
G(\alpha)<0 \quad \Leftrightarrow \quad 2 \alpha-1-\frac{\beta}{1-\beta(1-s)} \gamma \theta^{\alpha}<0
$$

If $\alpha=1 / 2$, then:

$$
G(1 / 2) \equiv-\frac{\beta}{1-\beta(1-s)} \gamma \theta^{1 / 2}<0
$$

The job finding rate is a strictly concave function of productivity when $\alpha=1 / 2$ (i.e at the rigid wage threshold). Because $2 \alpha-1<0$ for $\alpha<1 / 2$, this restriction is also satisfied for any $\alpha \in[0,1 / 2]$. Then, we deduce that the concavity of the job finding rate is more probable in the case of flexible wages. 